\title{
A review of Microdontinae (Diptera: Syrphidae) of Surinam, with a key to the Neotropical genera
}

\author{
Menno Reemer
}

The fauna of Microdontinae (Diptera: Syrphidae) of Surinam is reviewed, based on a recent field survey by the author and a re-evaluation of previously collected material, mostly deposited in the RMNH collection (Leiden). A key to all 28 Neotropical genera of the subfamily is given. A total number of 42 species belonging to 13 genera are recorded from Surinam. Habitus photographs of all species are given. Compared with the checklist of Van Doesburg (1966), 24 species are added and five are removed. The following new species are described: Domodon peperpotensis sp. n., Microdon (Microdon) colakriki sp. n., Peradon satyricus sp. n. and Peradon sciarus sp. n. Five possibly new species are left unnamed, pending revisionary work of the species groups they belong to. A neotype is designated for Aphritis angustus Macquart, 1846. The following new synonymies are proposed: Microdon instabilis Wiedemann, $1830=$ Microdon aurifex Wiedemann, 1830 jun. syn. n., Microdon batesi Shannon, $1927=$ Microdon beebei Curran, 1936 syn. n.

Keywords: Diptera, Syrphidae, Microdontinae, Surinam, Neotropical region, key, new species.

Menno Reemer, Naturalis Biodiversity Center, P.O. Box 9517, 2300 RA Leiden, the Netherlands. Menno.reemer@naturalis.nl

\section{Introduction}

Microdontinae (Diptera: Syrphidae) are unlike other hoverflies in several respects. The adults are rarely seen on flowers, and in some species they do not feed at all. Their diversity in shape, size and unusual morphological peculiarities can easily compete with those found among larger clades of Diptera Cyclorrhapha. The larvae are slug-like creatures, which have been described as molluscs on four independent occasions (see references in Reemer 2012). They live in ants nests as highly specialized predators of the ant brood, and can be considered potentially influential on ant populations and hence on ecosystems (for review see Reemer 2012, 2013a). So far, this group has received little attention of taxonomists, mostly due to the fact that they are so rarely encountered; the majority of described species is only known from one or a few specimens.
Worldwide, 476 species of Microdontinae are known. With 202 described species of Microdontinae, the Neotropical region is the richest of the major biogeographical regions for this subfamily (Reemer \& Ståhls 2013a, Reemer 2013b). Species identification in this region is difficult, because of poorly resolved taxonomy and the occurrence of a large number of undescribed taxa. Identification keys to genera of Microdontinae of the world have been published by Hull (1949), Cheng \& Thompson (2008) and Reemer \& Ståhls (2013a). Thompson (1969) and Thompson et al. (2010) presented keys to, respectively, Neotropical genera and Central American (sub)genera.

No keys to all species of Neotropical Microdontinae are available. Curran (1934) published a key to a total number of 14 species of Microdontinae (all included in the genus Microdon Meigen, 1803) known to him from British Guiana and Panama. 
Curran (1940) presented a key to 48 species of Microdon. The same key was also included in Curran (1941), in which paper also keys to 12 species of other genera belonging to Microdontinae are given. Van Doesburg (1966) provided a key to 10 species he included in the genus Ubristes Walker, based on the key of Shannon (1927). Thompson (1981) provided a key to six West Indian species of Microdon. Needless to say, with 202 species known from the Neotropical region and many more unknown, available keys to species are very incomplete.

Recently, Reemer \& Ståhls (2013a, b) revised the genera of Microdontinae, analyzed their phylogenetic relationships and classified all species. Species revisions of a few Neotropical genera were recently published by Reemer (2013b). These papers provide a taxonomic framework for the present paper.

This paper is part of a series of papers reviewing the fauna of Syrphidae of Surinam. A general introduction and the results for the subfamily Syrphinae can be found in Reemer (2010). The present paper deals with the subfamily Microdontinae, of which 42 species are now known from the country. New records are provided based on a field survey in Surinam by the author from December 2005 to April 2006. The old records and collection of Van Doesburg (1962, 1966), who recorded 24 species of Microdontinae from Surinam, are reviewed in the light of present taxonomical knowledge. A key to the Neotropical genera of the subfamily is presented.

\section{Material and methods}

Explanation of material and methods, as well as a list of collecting sites and acronyms of entomological collections, can be found in Reemer (2010). One additional collecting site is referred to in the present paper: Akintosoela $\left(05^{\circ} 16^{\prime} \mathrm{N}-54^{\circ} 55^{\prime} \mathrm{W}\right)$, district Para.

The following additional acronyms are used to indicate entomological collections: MIZUN (Museo dell'Instituto di Zoologia dell'Università di Napoli, Naples), MZH (Finnish Museum of Natural History, Helsinki), MZUSP (Museu de Zoologia da Universidade de São Paulo, São Paulo).

Unless stated otherwise, all specimens were collected by M. Reemer and preserved in the RMNH collection (Naturalis Biodiversity Center, Leiden). Classification follows Reemer \& Ståhls (2013a), on which also the key to the genera is based. Identifications are largely based on the examination of type specimens by the present author. Specimens of Ceratophya Wiedemann, 1830 and Stipomorpha Hull, 1945 were identified using the keys in Reemer (2013b).

\section{Results}

A total number of 42 species of Microdontinae are recorded from Surinam in this paper. Four species are described here for the first time: Domodon peperpotensis sp. n., Microdon (Microdon) colakriki sp. n., Peradon satyricus sp. n. and Peradon sciarus sp. n. Habitus photographs of all species are given in Figs 1-52.

Compared with the checklist of Van Doesburg (1966), five species are removed and 24 are added (Table 1). Unless stated otherwise, references to "previous records" concern the papers by Van Doesburg (1962, 1966), and "new records" are from the present author.

\section{Carreramyia Van Doesburg, 1966}

Carreramyia is one of the Neotropical genera in which the basoflagellomere of the male is bifurcate. Unlike the other genera, the species are mimics of Trigona-like stingless bees. Four species are described (Reemer 2013b), one of which is known from Surinam.

\section{Carreramyia megacera Reemer}

Fig. 51

Carreramyia megacera Reemer, 2013: 12. Holotype: Surinam, Peperpot (RMNH). [examined]

Notes. This species is a mimic of black Trigona-like stingless bees. Only one specimen is known.

New records. Peperpot, Malaise trap, 17-24.ii.2006, 1 ㅇ.

\section{Ceratophya Wiedemann, 1830}

The Neotropical genus Ceratophya is one of the few genera in which abdominal tergites 3 and 4 are not fused. Especially in the female, the abdomen seems to be strongly telescopically extendable, presumably enabling it to oviposit in deep crevices. Five species are described, which kan be identified using the key in Reemer (2013b).

\section{Ceratophya notata Wiedemann}

Fig. 10

Ceratophya notata Wiedemann, 1824: 14. Holotype: Brazil (NMW). [examined]

Microdon panamensis Curran of Van Doesburg (1966: 83), misidentification.

Notes. This specimen was previously identified as Microdon panamensis Curran by Van Doesburg (1966). However, examination of the type of $M$. panamensis revealed that it is not the same species. Differences with $M$. panamensis are, among other, the unsulcate scutellum and the abdominal coloura- 


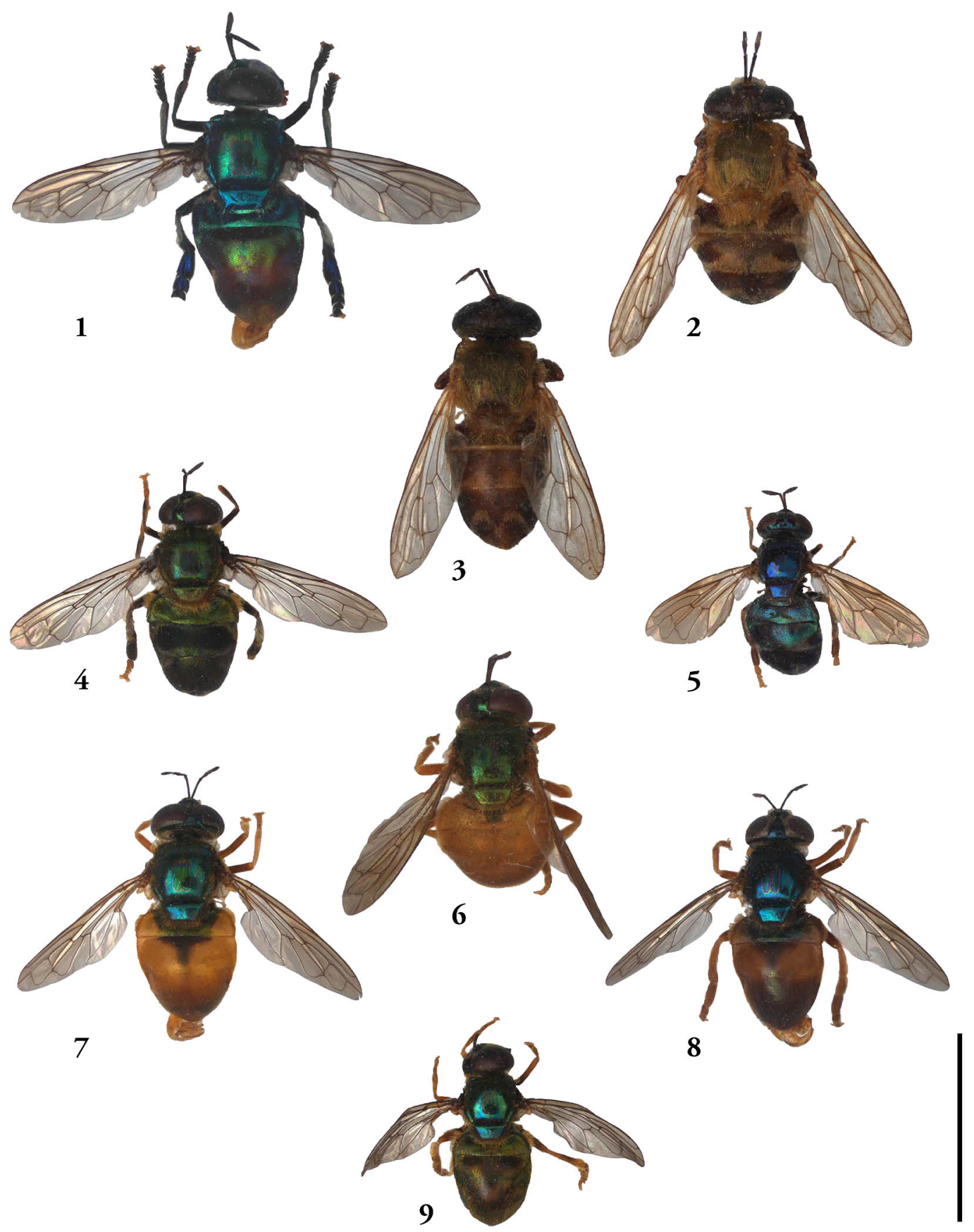

Figs 1-9. Dorsal habitus of Microdon species. - 1, M. (Chymophila) SUR-02 male, Peperpot 24.ii.2006; 2, M. (Chymophila) stramineus female, Nassau Mts. 11.iii.1949; 3, M. (Chymophila) stramineus male, Nassau Mts. 11.iii.1949; 4, M. colakriki male, Colakreek 9.iii.2006, holotype; 5, M. brutus female, Albina 26.iv.1963; 6, M. rufiventris female, Perica 15-29.x.1997; 7, M. rufiventris male, Brownsberg 5.ii.2006; 8, M. rufiventris male (dark form), Fungu Island 15.ii.2006; 9, M. virgo male, Brownsberg 4.iii.2006. Scale bar: $10 \mathrm{~mm}$. 


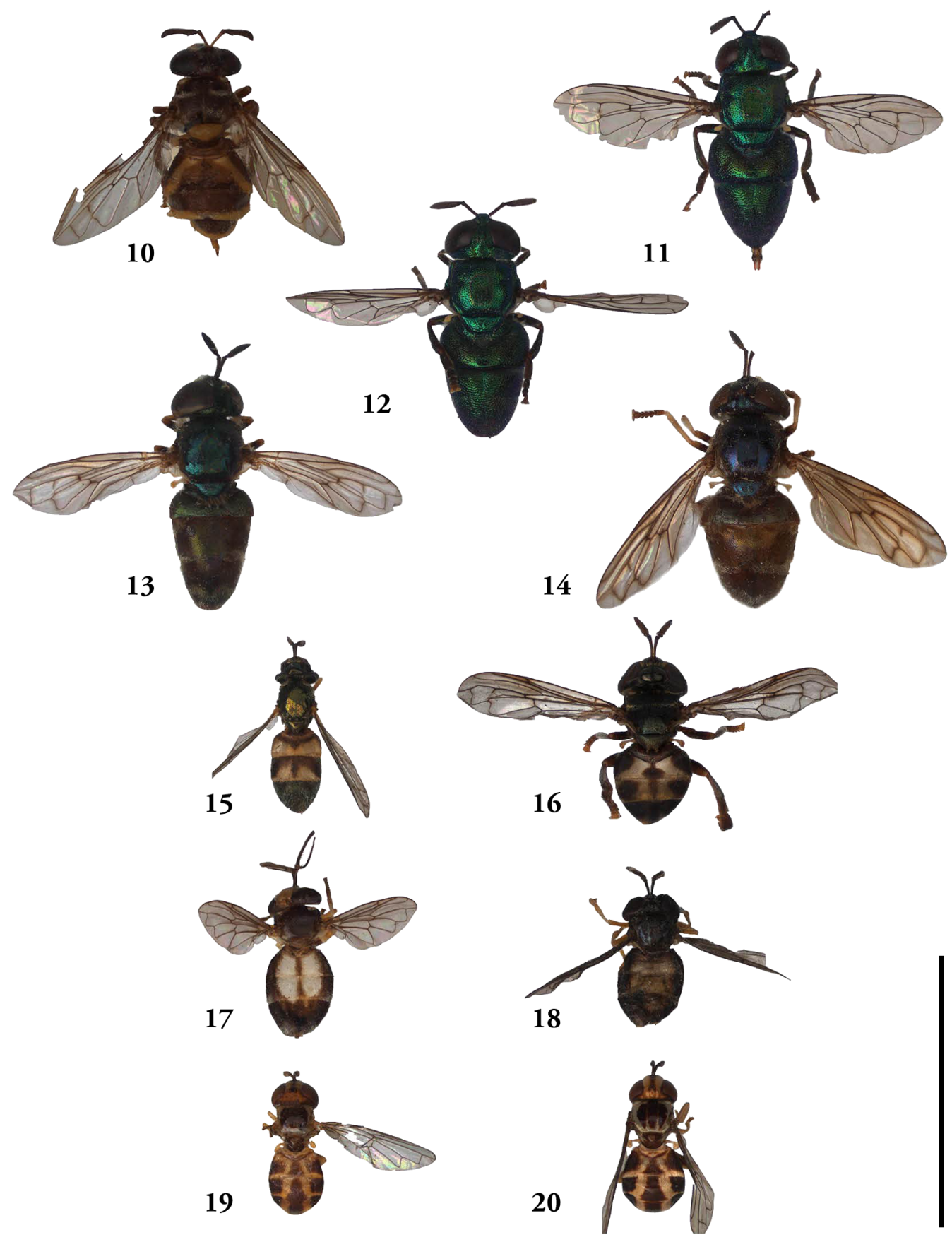

Figs 10-20. Dorsal habitus of Microdontinae. - 10, Ceratophya notata female, Zanderij 18-21.vii.1964; 11, Chrysidimyia chrysidimima female, Republiek 17.viii.1961; 12, Chrysidimyia chrysidimima male, Republiek 17.viii.1961; 13, Laetodon geijskesi male, Paramaribo 4.vii.1962 (paratype); 14, Laetodon geijskesi female, Kwatta 28.i-1.ii.1964 (paratype); 15, Domodon peperpotensis male, Peperpot 6-14.iv.2006 (holotype); 16, Domodon zodiacus male, Paramaribo zoo 18-27.ii.2006 (holotype); 17, Schizoceratomyia barretoi male, Zanderij 11.v.1963; 18, Schizoceratomyia flavipes male, Brownsberg 4.iii-1.iv.2006; 19, Surimyia minutula male, Zanderij 13-16.viii.1964 (holotype); 20, Surimyia rolanderi female, Peperpot 14-21.iii.2006. Scale bar: $10 \mathrm{~mm}$. 

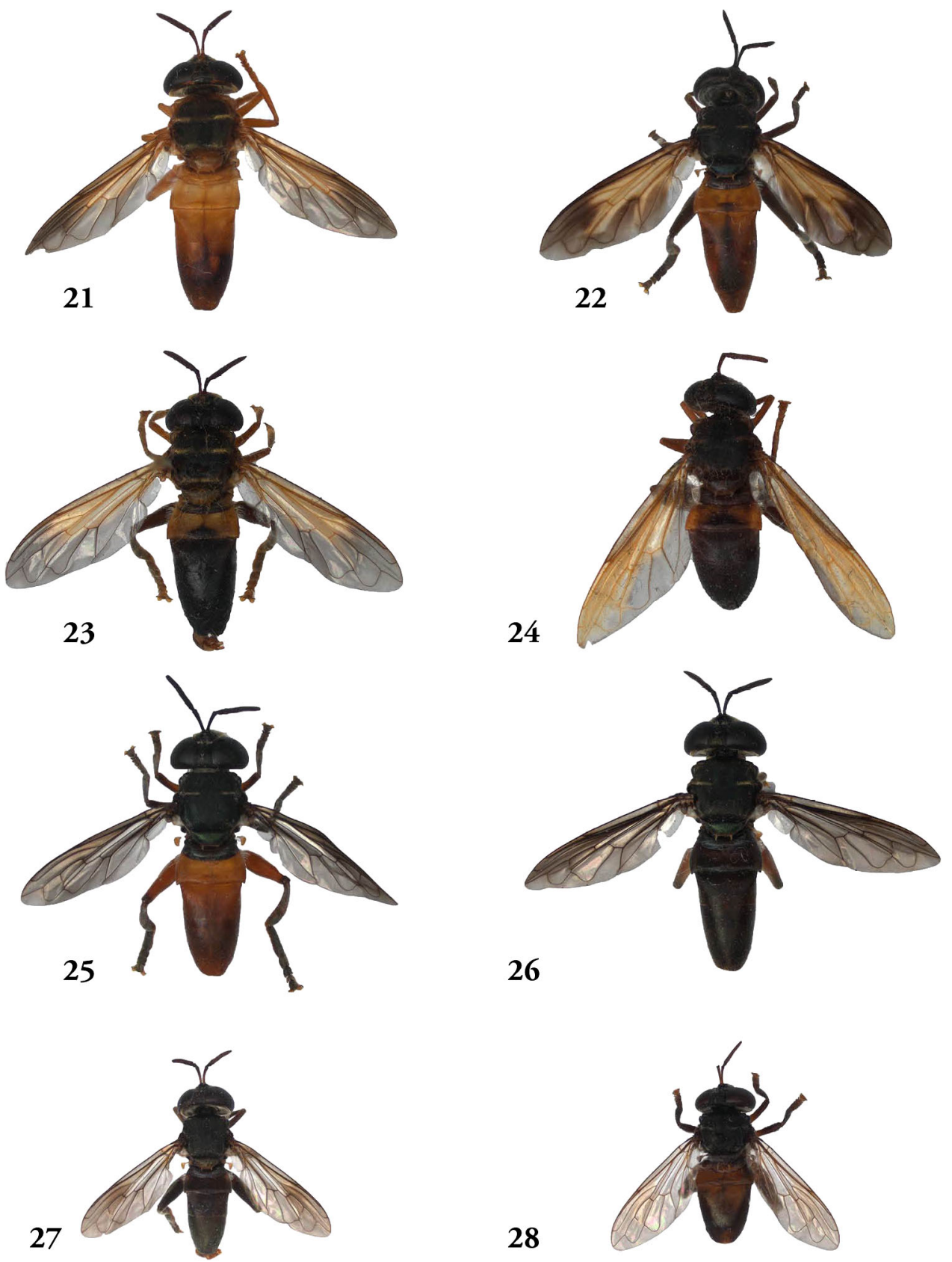

Figs 21-28. Dorsal habitus of Peradon species. - 21, P. angustiventris male, Colakreek 30.iii.2006; 22, P. angustus female, Mopentibo 19.iv.2006; 23, P. luridescens male, Nason 19.iii.2006; 24, P. luridescens female, Brownsberg 14.ix.1938; 25, P. bidens male, Zanderij 16.iii.2006; 26, P. langi male, Zanderij 30.iii.2006; 27, P. sciarus male, Awarradam 13.iv.2006 (holotype); 28, P. satyricus male, Brownsberg 2.iv.2006 (holotype). Scale bar: $10 \mathrm{~mm}$. 


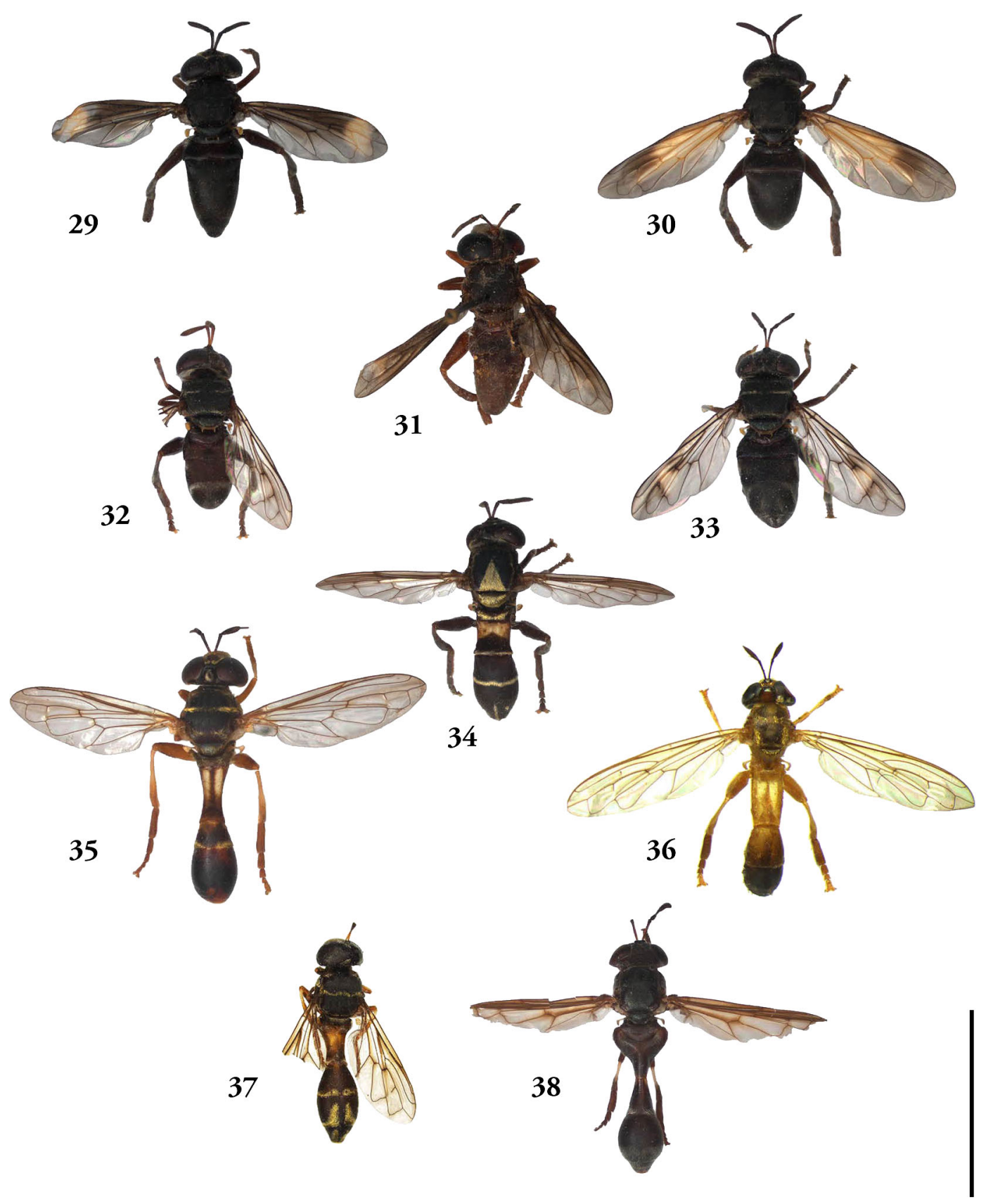

Figs 29-38. Dorsal habitus of Microdontinae. - 29, Peradon SUR-17a female, Brownsberg 2.iv.2006; 30, P. SUR-17b female, Brownsberg 2.iv.2006; 31, P. SUR-18 male, 'Surinam'; 32, P. flavofascium male, Raleigh Falls 16.vii.1963; 33, P. flavofascium female, Colakreek 30.iii.2006; 34, P. trivittatum male, Carolinakreek 30.iv.1962; 35, Pseudomicrodon batesi male, Phedra 14.xii.1964; 36, Pseudomicrodon nigrispinosus male, Republiek 18.iv.1960; 37, Pseudomicrodon SUR-22 female, Zanderij 21.viii.1963; 38, Rhopalosyrphus guentherii male, Paramaribo 2.v.1962. Scale bar: $10 \mathrm{~mm}$. 

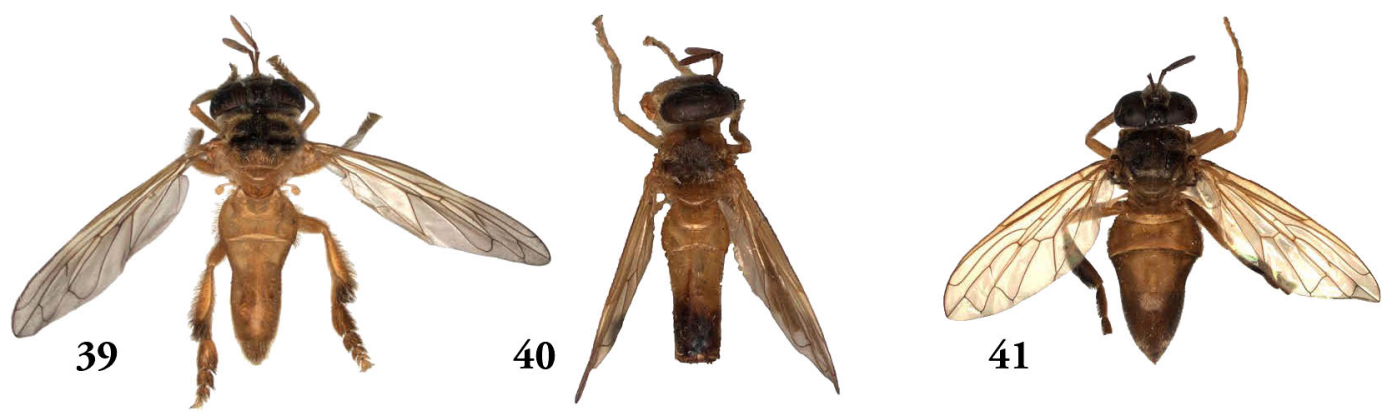

42
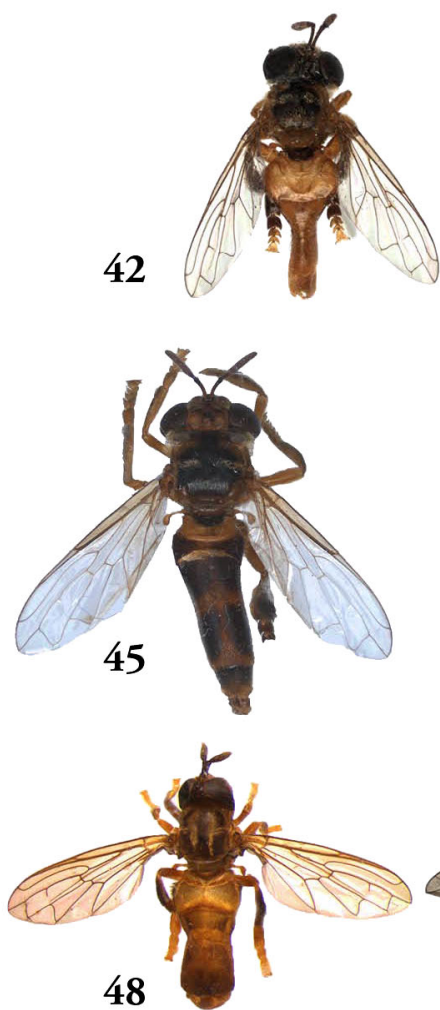

43
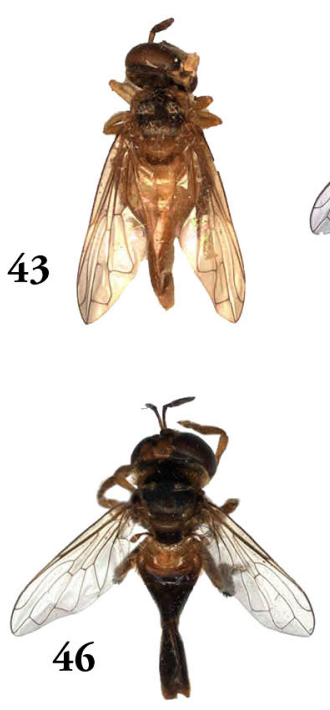
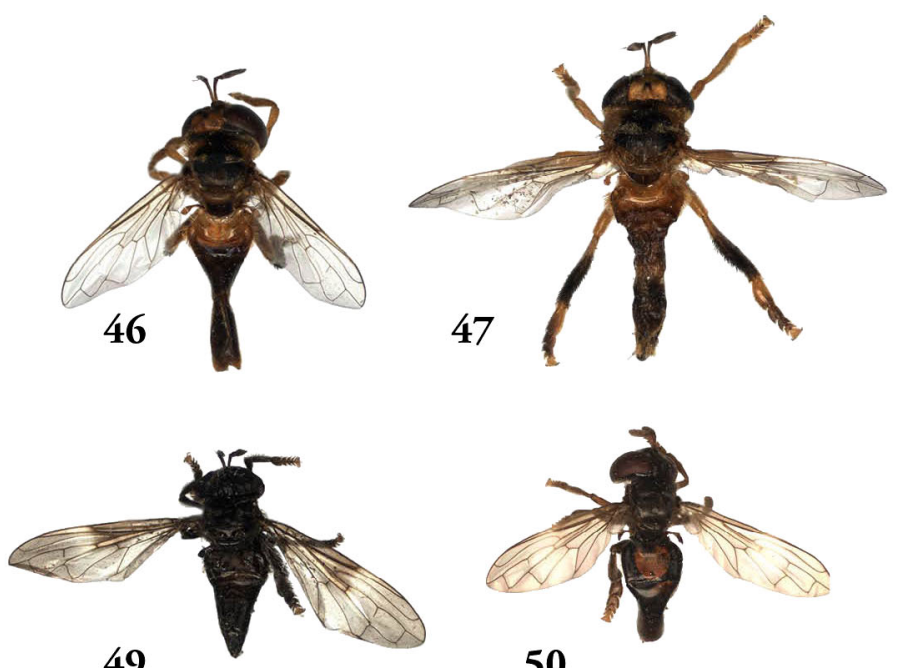

49

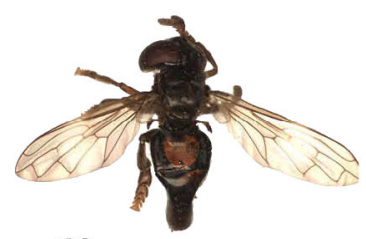

50
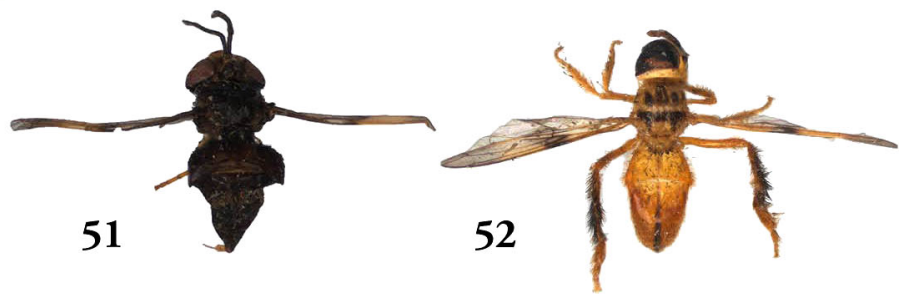

Figs 39-52. Dorsal habitus of Microdontinae. - 39, Stipomorpha mackiei female, Oost-Westverbinding $70 \mathrm{~km} \mathrm{E}$ Paramaribo 21.x.1995; 40, S. mackiei male, Charlesburg 21.i.1964; 41, S. mixta female, Brownsberg 2.iv.2006; 42, S. mendax male, Ma Retraite 14.i.1964 (paratype); 43, S. mendax female, Kwatta 1.ii.1964 (paratype); 44, S. spuria male, Peperpot 20.iv.2006 (holotype); 45, S. goettei female, Zanderij road to Kraka 16.iii.2006; 46, S. guianica male, Peperpot 28.iii.2008; 47, S. guianica female, Peperpot 2-9.ii.2006; 48, S. lanei male, Paramaribo 9.xii.1957; 49, S. lacteipennis female, Peperpot 20-27.iv.2006; 50, S. puerilis female, Zanderij 23.ix.1960; 51, Carreramyia megacera female, Peperpot 17-24.ii.2006 (holotype); 52, Rhoga SUR-01 female, Peperpot 9-17.ii.2006. 
Table 1. Overview of proposed changes in the checklist of Syrphidae (subfamily Microdontinae) of Surinam, compared with the list of Van Doesburg (1966). For details see species accounts.

\author{
Species added to the checklist (24) \\ Carreramyia megacera Reemer, 2013 \\ Ceratophya notata Wiedemann, 1824 \\ Domodon peperpotensis sp. $\mathrm{n}$. \\ Domodon zodiacus Reemer, 2013 \\ Microdon (Chymophila) stramineus Hull, 1943 \\ Microdon (Chymophila) SUR-02 \\ Microdon (Microdon) rufiventris (Rondani, 1848) \\ Microdon (Microdon) virgo Curran, 1940 \\ Microdon (Microdon) colakriki sp. n. \\ Peradon langi (Curran, 1925) \\ Peradon luridescens (Walker, 1857) \\ Peradon satyricus sp. $\mathrm{n}$. \\ Peradon sciarus sp. $\mathrm{n}$. \\ Peradon SUR-17a \\ Peradon SUR-17b \\ Peradon SUR-18 \\ Pseudomicrodon SUR-22 \\ Rhoga SUR-01 \\ Schizoceratomyia flavipes Carrera, Lopes \& Lane, 1947 \\ Stipomorpha guianica (Curran, 1925) \\ Stipomorpha mendax Reemer, 2013 \\ Stipomorpha mixta (Curran, 1940) \\ Stipomorpha spuria Reemer, 2013 \\ Surimyia rolanderi Reemer, 2008 \\ Species removed from the checklist (5) \\ Microdon fulgens Wiedemann, 1830 \\ Microdon normalis Curran, 1925 \\ Microdon panamensis Curran, 1930 \\ Ubristes fraudator (Shannon, 1927) \\ Ubristes simillima (Hull, 1950)
}

misid. of Microdon (Chymophila) SUR-02 misid. of Peradon SUR-18

misid. of Ceratophya notata Wiedemann, 1824 misid. of Stipomorpha mendax Reemer, 2013 specimen lost

\footnotetext{
Name changes (synonyms and different combinations) (9)

Van Doesburg (1962, 1966)

Ceratophya minutula Van Doesburg, 1966

Microdon granulatus Curran, 1940

Microdon lanei Curran, 1936

Microdon angustiventris (Macquart, 1855)

Microdon angustus (Macquart, 1846)

Microdon bidens (Fabricius, 1805)

Microdon flavofascium Curran, 1925

Microdon nigrispinosus Shannon, 1927

Microdon trivittatum Curran, 1925

Pseudomicrodon beebei Curran, 1936

Ubristes goettei (Shannon, 1927)

Ubristes lacteipennis (Shannon, 1927)

Ubristes mackiei (Curran, 1940)

Ubristes puerilis Van Doesburg, 1966

\section{Present publication}

Surimyia minutula (Van Doesburg, 1966)

Chrysidimyia chrysidimima Hull, 1937

Stipomorpha lanei (Curran, 1936)

Peradon angustiventris (Macquart, 1855)

Peradon angustus (Macquart, 1846)

Peradon bidens (Fabricius, 1805)

Peradon flavofascium (Curran, 1925)

Pseudomicrodon nigrispinosus (Shannon, 1927)

Peradon trivittatum (Curran, 1925)

Pseudomicrodon batesi (Shannon, 1927)

Stipomorpha goettei (Shannon, 1927)

Stipomorpha lacteipennis (Shannon, 1927)

Stipomorpha mackiei (Curran, 1940)

Stipomorpha puerilis (Van Doesburg, 1966)
}

tion. Instead, the specimen agrees well with the Brazilian holotype of Ceratophya notata Wiedemann, 1824 , although that type is a male while the specimen from Surinam is a female.

Previous records. Zanderij, 18-21.vii.1964, leg. D.C. Geijskes, 1 ․

\section{Chrysidimyia Hull, 1937}

The only described species of the Neotropical genus Chrysidimyia is a remarkably good mimic of a cuckoo wasp (Hymenoptera: Chrysididae). 


\section{Chrysidimyia chrysidimima Hull}

Figs 11, 12, 53

Chrysidimyia chrysidimima Hull, 1937: 116. Holotype: Brazil, Santarém (CM). [examined]

Microdon granulatus Curran, 1940: 9. Holotype: Guyana, Mazaruni (BMNH). [examined]

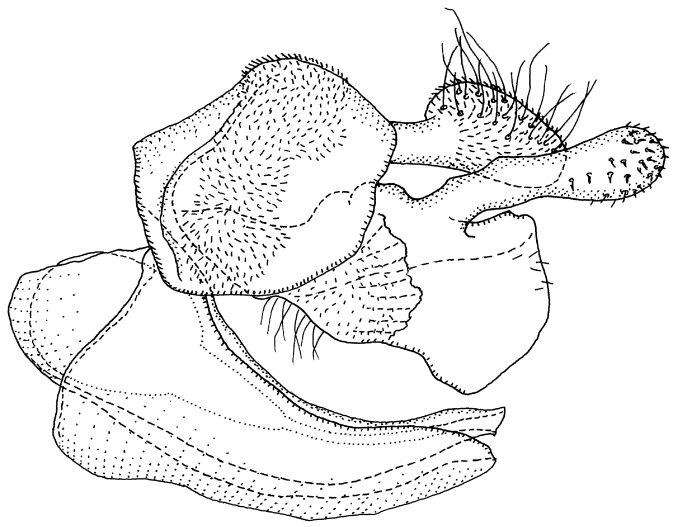

Fig. 53. Chrysidimyia chrysidimima, Republiek 17.viii.1961, male genitalia, lateral view.
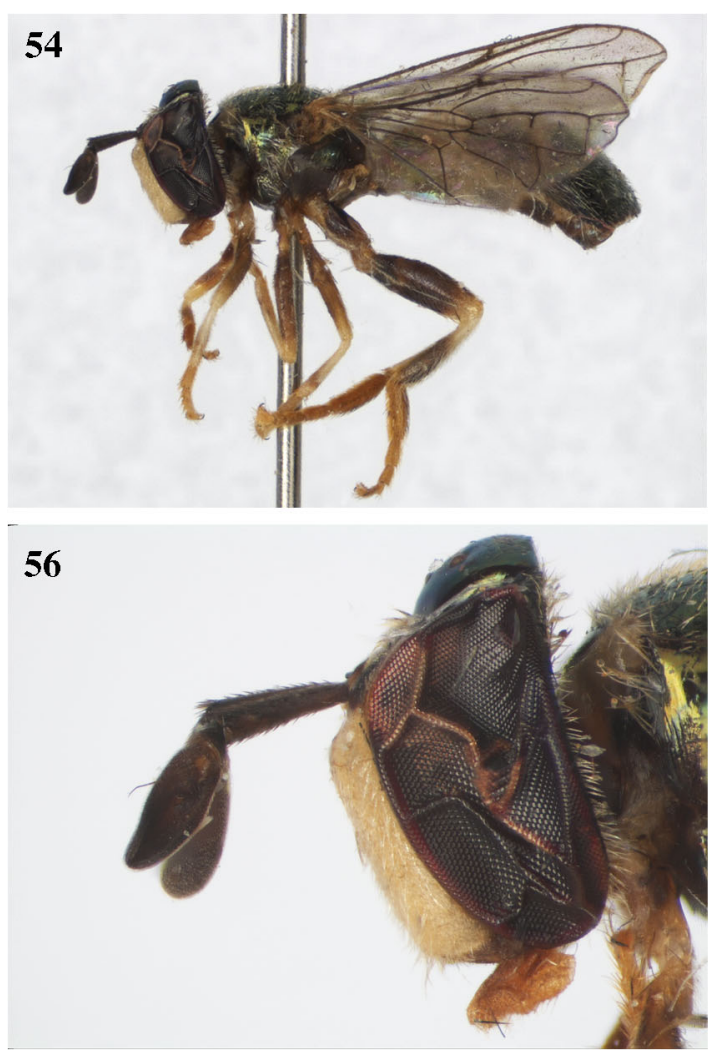

Chrysidimyia lazuli Hull, 1944: 241. Holotype: Brazil, Villa Nova (BMNH). [examined]

Microdon granulatus Curran: Van Doesburg (1966: 82).

Notes. The genitalia of the male specimen from Surinam are figured in Fig. 53 (compare with figure of genitalia of holotype of $C$. chrysidimima in Reemer \& Ståhls 2013a).

Previous records. Republiek, 17.viii.1961, leg. P.H. van Doesburg Jr., $10^{\Uparrow} 1$ \% .

\section{Domodon Reemer, 2013}

The Neotropical genus Domodon was described by Reemer in Reemer \& Ståhls (2013a), based on a specimen of D. zodiacus Reemer, 2013 from Surinam. Here another species is described in this genus, also from Surinam.

\section{Domodon peperpotensis sp. $\mathbf{n}$.}

Figs 15, 54-57

Type material. Holotype $\sigma^{7}$ : Peperpot, Malaise trap, 6-14.iv.2006, leg. M. Reemer (RMNH).
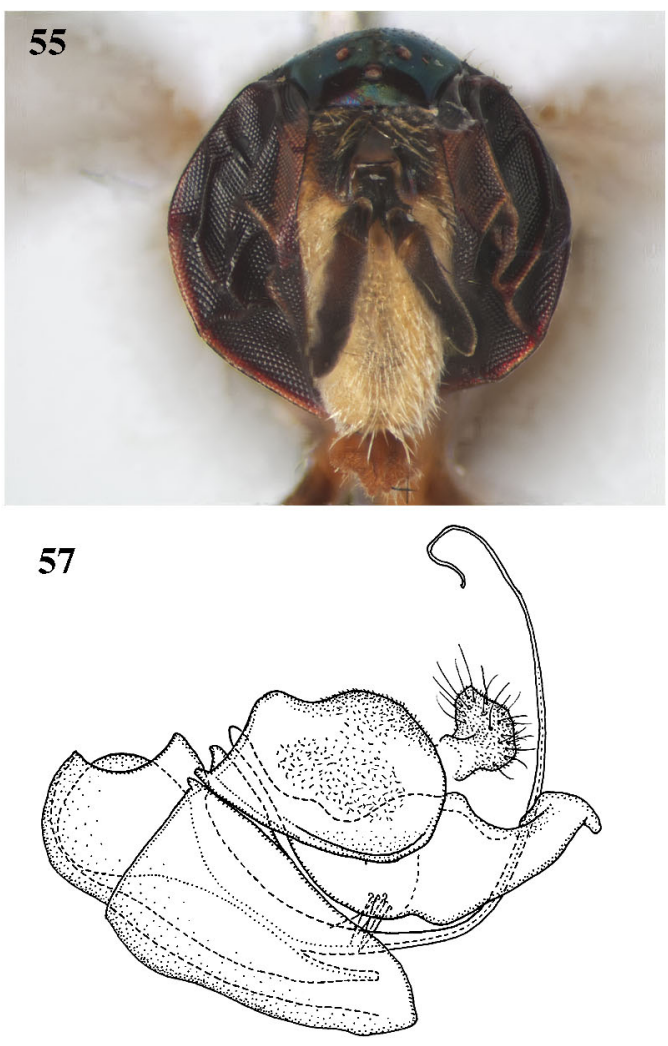

Figs 54-57. Domodon peperpotensis sp. n. male (holotype). - 54, habitus lateral; 55, head frontal; 56, head lateral; 57 , genitalia lateral. 


\section{Diagnosis}

This species differs from Domodon zodiacus Reemer, 2013, the only other described species of Domodon, in the narrower abdomen and the metallic green mesoscutum.

\section{Description of adult male (based on holotype) Body length: $6 \mathrm{~mm}$.}

Head. Dichoptic. Face pale yellow, occupying between $1 / 4$ and $1 / 3$ of total head width in frontal view; entirely yellow pilose; not pollinose; eye margins slightly converging at level of frons, with smallest distance approximately equal to three times width of antennal fossa. Gena hardly developed; black. Oral margin laterally slightly produced; black. Antennal fossa about as wide as high. Frons black with metallic green shine; golden pilose. Vertex convexly produced; black with metallic green shine; bare. Ocellar triangle not elevated; frontal angle about $90^{\circ}$. Occiput narrow; black with metallic green shine; golden yellow pilose dorsally, white pilose ventrally. Eye bare. Antenna black; antennal ratio approximately 4:1:4; basoflagellomere parallel-sided with rounded apex, with small sensory pit located at about $1 / 2$ of length; arista slender, about $2 / 3$ of length of basoflagellomere.

Thorax. Mesoscutum, postalar callus and scutellum black with metallic green shine; yellow pilose. Postpronotum yellow; yellow pilose. Scutellum with two apical calcars of $1 / 3$ of length of scutellum. Pleurae black with metallic green shine, except katepimeron, meron and hypopleuron brownish yellow. Anepisternum with anterior and posterior part separated by shallow sulcus; anterior and posterior parts pale yellow pilose, with bare area in between. Anterior anepimeron entirely pale yellow pilose. Katepisternum yellow pilose dorsally, bare ventrally. Katatergum with long black microtrichia. Anatergum short black microtrichose. Other pleurae bare. Calypter and halter yellow.

Wing - Hyaline; microtrichose, except bare on 1st costal cell, posterobasal $1 / 3$ of 2 nd costal cell, basally on cell $r 1$ along vein RS, on cell $r$ except along vena spuria, on posterobasal $2 / 3$ of cell bm, on anterobasal $1 / 2$ of cell cup.

Legs - Fore- and mid-legs: femora brownish with pale yellow apical $1 / 4$, tibiae pale yellow, tarsae dark yellow; entirely yellow pilose. Hind-leg: femur blackish with pale yellow apical $1 / 5$, tibia blackish with pale yellow basal $2 / 5$, tarsus dark yellow; yellow pilose except dorsal surface of first tarsomere black pilose. Fore- and mid-coxae and trochanters yellow; yellow pilose. Hind-coxae blackish and yellow pilose, hind trochanters yellow and yellow pilose.

Abdomen. Ratio of median tergal lengths approximately as 1:2:3:5. Tergites 3 and 4 not fused. Ter- gite 1 blackish brown medially, yellow along margins; yellow pilose. Tergite 2 pale yellow except black along anterior and lateral margins and with anterior black margin medially somewhat extended posteriorly; entirely yellow pilose. Tergite 3 with similar colouration as tergite 2 , but black markings more extensive and covering entire anterior half of tergite and entire lateral margins; yellow pilose except black pilose on anterior black parts. Tergite 4 entirely black with metallic green shine; white pilose. Sternites brownish; quite small, surrounded by wide, pale yellow membraneous parts; pale pilose, except sternite 1 bare. Genitalia as in Fig. 57.

\section{Etymology}

The name peperpotensis refers to the type locality: Peperpot, a former coffee- and cocoa-plantation.

\section{Domodon zodiacus Reemer}

Fig. 16

Domodon zodiacus Reemer in Reemer \& Ståhls, 2013: 97. Holotype: Surinam, Paramaribo Zoo (RMNH). [examined]

Previous records. Paramaribo Zoo, Malaise trap, 1827.ii.2006, leg. M. Reemer, 1 ơ (Reemer \& Ståhls 2013a).

\section{Laetodon Reemer, 2013}

Laetodon is a New World genus with four described Nearctic species, and one Neotropical species.

\section{Laetodon geijskesi (Van Doesburg)}

Figs 13, 14

Microdon geijskesi Van Doesburg, 1966: 80. Holotype: Surinam (RMNH). [examined]

Notes. The species boundaries and intraspecific variation between the species of Laetodon are not clear, so further study is necessary to establish the taxonomic status of M. geijskesi.

Previous records. Paramaribo, 2.vi.1957, leg. P.H. van Doesburg Jr., 1 o; Paramaribo, ix.1957, leg. P.H. van Doesburg Jr., $1 \sigma^{7}$ (paratype); Paramaribo, 4.vii.1962, leg. P.H. van Doesburg Jr., $1 \sigma^{7}$ (paratype); Domburg, 13.xii.1963, leg. D.C. Geijskes, 1 \%; Kwatta, Parwabos, 1.ii.1964, leg. D.C. Geijskes, $10^{\text {T }}$ (holotype) 1 ㅇ (paratype).

\section{Microdon Meigen, 1803}

Until recently, Microdon was one of the largest genera of Syrphidae, competing in species number only with Copestylum Macquart, 1846 and Ocyptamus Macquart, 1834. Reemer \& Ståhls (2013a, b) revised the 
concept of this genus and 126 species were validated, 62 of which are known from the Neotropical region. Six species were found in Surinam. Two of those belong to the New World subgenus Chymophila Macquart, 1834, four to the Neotropical virgo species group of the subgenus Microdon. Species of Chymophila are known to be associated with ants of the subfamilies Formicinae and Myrmicinae. No hostassociations are known for species of the virgo-group (Reemer 2013a).

\section{Microdon (Chymophila) stramineus Hull}

Figs 2, 3

Microdon straminea Hull, 1943: 703. Holotype: Brazil (Pará) (BMNH). [examined]

Notes. The specimens from Surinam were compared with the holotype. They seem to belong to the same species, although in the holotype the oblique fasciae of black pile on the tergites are narrower. This species shares the pattern of pale pilose fasciae on the tergites with $M$. flavoluna Hull, $M$. histrio Wiedemann, $M$. shannoni Curran, $M$. superbus Wiedemann and $M$. tigrinus Curran. From all these species, M. stramineus differs because the pale fasciae of pile are less conspicuous: relatively short and straw-coloured instead of long, thick and whitish yellow. The male genitalia were figured by Reemer \& Ståhls (2013a).

Although the specimens of this species are old, they had apparently not been upon Van Doesburg's notice, for he did not record it in his papers, nor do they carry his identification labels.

New records. Nassau Mts., 11.iii.1949, leg. D.C. Geijskes, $10^{7} 1$ ㅇ.

\section{Microdon (Chymophila) SUR-02}

Fig. 1

Microdon fulgens Wiedemann, 1830 of Van Doesburg (1962: 12, 1966: 80).

Notes. This species belongs to Microdon subgenus Chymophila Macquart as defined by Reemer \& Stăhls (2013a). This group contains several described Neotropical species, of which the following are of bright metallic blue-green colouration: $\mathrm{Mi}$ crodon aurifex Wiedemann, M. fulgens Wiedemann, $M$. instabilis Wiedemann (=M. aurifex Wiedemann, syn. n.), Chymophila splendens Macquart, and $M$. trochilus Walker. The types of these species were compared with the available Surinam and French Guyanan specimens and the noticed differences are given in Table 2.

The types of $M$. aurifex and $M$. instabilis are as good as identical in colouration of body and pile, external morphology and genitalia. Therefore, these

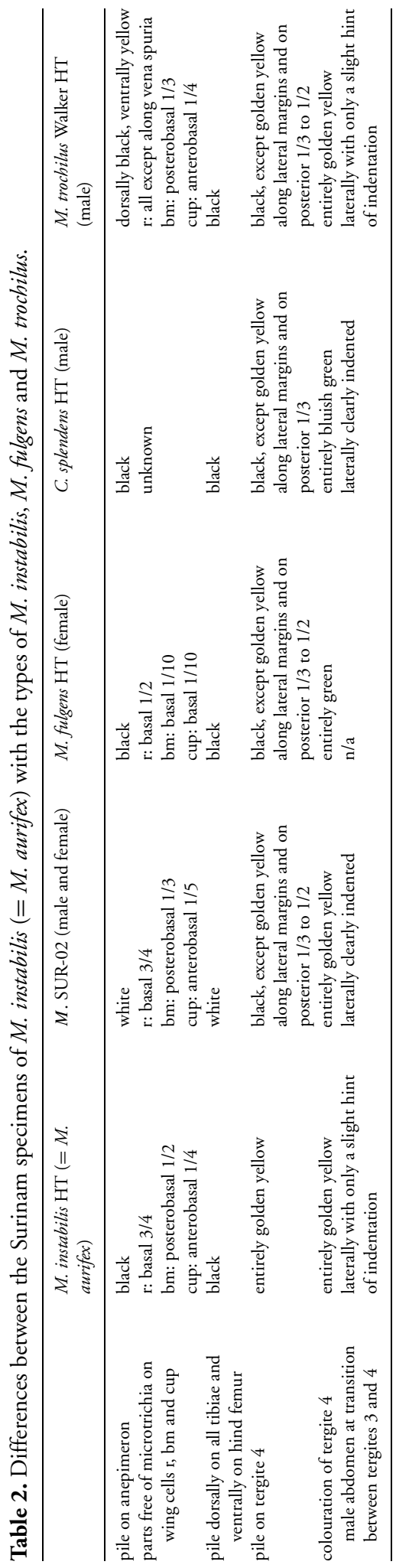


taxa are here considered synonyms, with $M$. instabilis as the senior name, as it was described two pages earlier. It may seem unlikely for Wiedemann to have described the same species twice within the same publication. However, at that time, the type of $M$. instabilis was in the collection of the Zoological Museum in Berlin ("Im Berliner Museum"), while the type of $M$. aurifex was in Wiedemann's personal collection ("In meiner Sammlung"), presumably in Kiel. So he has probably not compared the specimens directly and had to rely on his descriptions, which although quite accurate - do not provide the detail required for a good comparison of both taxa. In his description, Wiedemann only compared $M$. aurifex with Mulio aurulentus Fabricus, 1805, whilst comparing $M$. instabilis with $M$. fulgens Wiedemann.

Based on the differences as given in Table 1, the specimens from Surinam may be considered to belong to an undescribed species. From all other metallic blue-green taxa of Microdon (Chymophila), Microdon SUR-02 differs by the white pile on the anepimeron and on the dorsal side of the tibiae. Although the characters as given are consistent in all 13 specimens (from three different localities in Surinam and French Guyana), the variability of these characters in the other taxa is unknown. For this reason, Microdon (Chymophila) SUR-02 is not formally described here, pending better understanding of the variability of the described characters in metallic blue-green Neotropical species of the subgenus Chymophila.

All recent records from Surinam are from a moist secondary forest on clay soil. One of the male specimens was observed displaying territorial behaviour, sitting on a sunlit leave in the forest at $50 \mathrm{~cm}$ above the ground, from where it made short flights after which it returned to the leaves again.

Previous records. Paramaribo, 14.iv.1938, leg. D.C. Geijskes, 1 \%; Paramaribo, 20.i.1960, leg. P.H. van Doesburg Jr., 1 q.

New records. Peperpot: 24.ii.2006, $1 \sigma^{\top} ; 21-28 . i i i$. 2006, $1 \sigma^{7}$; 28.iii-6.iv.2006, 1 o $^{7} 2$ \%; 6-14.iv.2006, $1 \sigma^{7} 1$ क; 14-20.iv.2006, 1 o $^{7}$; 20-27.iv.2006, $1 \sigma^{7}$ 1 ㅇ.

Additionally studied specimens. French Guyana: Roura, Kaw Road, PK 37, Relais Patawa, $4^{\circ} 32^{\prime} 42^{\prime \prime} \mathrm{N}-$ $52^{\circ} 9^{\prime} 9^{\prime \prime}$ W, vii.2009, leg. J.A. Cerda, 1 ( RMNH).

Studied type specimens of related taxa. HOLOTYPE Microdon instabilis Wiedemann. Male. Label 1 (blue): "Brasil. Langu [?]"; label 2: "879"; label 3 (red): "Type"; label 4 (blue): "instabilis / Wied.*”; label 5: "Zool. Mus. / Berlin". Coll. ZMB.

HOLOTYPE Microdon aurifex Wiedemann, 1830. Male. Label 1: "Brasilia, coll. Winthem"; label 2: "aurifex det. Wiedem."; label 3: "aurifex Wied Brasilia"; label 4 (yellow): "Lectotype Microdon au-

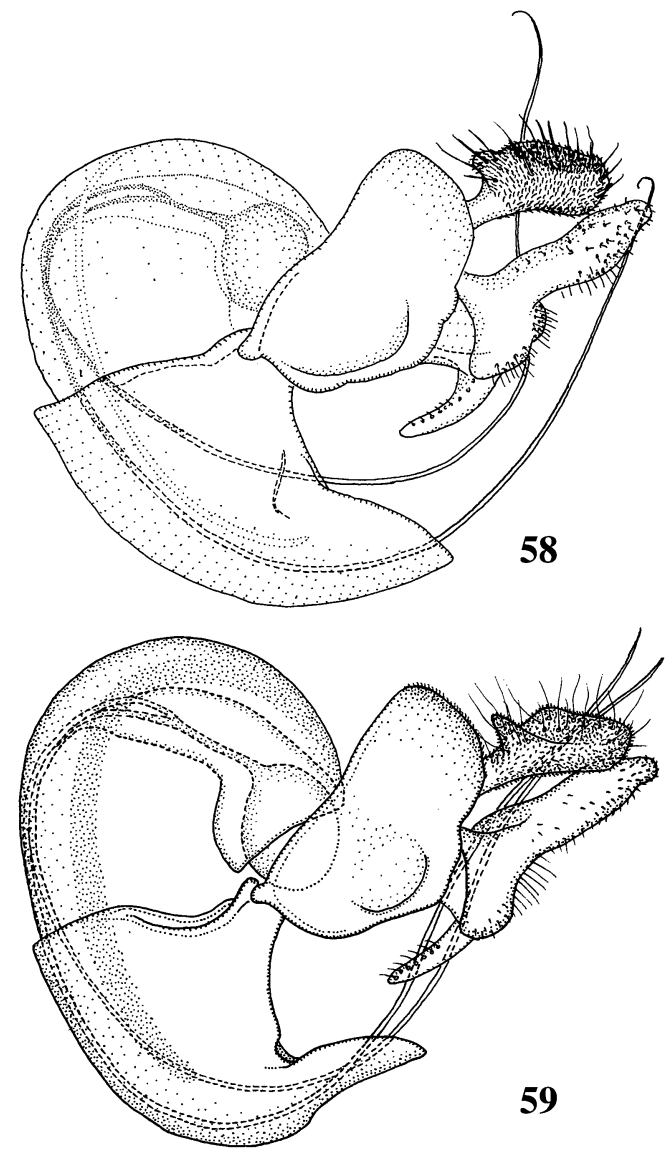

Figs 58, 59. Microdon (Chymophila), male genitalia. 58, $M$. aurifex holotype; 59, M. instabilis holotype.

rifex Wied. Design. Thompson 1977”. Coll. NMW. [Despite the label information, no lectotype designation has been published. The description of Wiedemann (1830) gives no reason to suspect that more than one specimen has been studied for the description, so the examined specimen is considered as a holotype.]

HOLOTYPE Microdon fulgens Wiedemann. Female. Label 1 (blue): "Georg. Escher"; label 2: "878"; label 3 (red): "Type"; label 4: "Coll. / H. Loew"; label 5 (blue): "fulgens / Wied.*”; label 6: "Zool. Mus. / Berlin”. Coll. ZMB.

HOLOTYPE Chymophila splendens Macquart, 1834. Male. Label 1 (small, round, red-bordered): "Holo-type"; label 2: "C. splendens / ex coll. Bigot". Label in drawer reads: "C. splendens [female sign] / Typ. artificial. ex. capit. / Conoptidid et corpus Aphritis / [illegible]". Coll. OUMNH.

HOLOTYPE Microdon trochilus Walker. Male. Label 1 (round, red-bordered): "Holo- / type"; la- 
bel 2: "Mexico"; label 3: "Microdon / dives, Rond. / trochilus / Wlk. / (Type)." Coll. BMNH.

\section{Microdon (Microdon) brutus Hull}

Fig. 5

Microdon brutus Hull, 1944: 37. Holotype: Brazil (Bahia). (CU). [examined]

Microdon brutus Hull: Van Doesburg (1966: 79).

Notes. Van Doesburg (1966) is uncertain about the identification of his specimens as M. brutus Hull. However, the identification could be confirmed by the present author after comparison with the holotype. In the specimens from Surinam the face is slightly wider and the scutellar calcars are a little longer. Otherwise they are very similar to the type and therefore they are considered to belong to the same species. So far, only females of this species are known.

Previous records. Paramaribo, 9.i.1958, leg. P.H. van Doesburg Jr., 1 \%; Albina, 26.vi.1963, leg. J. van der Vecht, 1 o.

New records. Peperpot, 28.iii-6.iv.2006 (malaise trap), leg. M. Reemer, 1 q.

\section{Microdon (Microdon) colakriki sp. $\mathbf{n}$.}

Figs 4, 60-62

Type material. Holotype $\sigma^{7}$ : Colakreek, 9.iii.2006, leg. M. Reemer (RMNH).

\section{Diagnosis}

This species runs to Microdon virgo Curran in the last published key to Neotropical Microdon species (Curran 1941). Within Microdon (Microdon), as defined by Reemer \& Ståhls (2013a), both M. virgo and $M$. colakriki sp. n. belong to a group of Neotropical species with the following characters: thorax and abdomen (almost) entirely metallic blue or green, postero-apical corner of cell $\mathrm{r} 4+5$ widely rounded, vein M1 not recurrent anteriorly, abdomen wide. Other species belonging to this group are: $M$. aureopilis Marinoni, M. barbouri Hull, M. bassleri Curran, M. brutus Hull, M. caesar Curran, M. crassitarsis Macquart, M. mourei Thompson and $M$. remus Curran. From all of these species $M$. colakriki differs by the combination of the following characters: femora entirely black, front- and mid-tarsi entirely yellow, hind tarsus with first tarsomere black and other tarsomeres yellow, tergite 3 dull black with metallic green anterior, posterior and lateral margins. Microdon rufiventris Rondani is also related, but that species is readily distinguished by it's predominantly orange abdomen.

\section{Description of adult male (based on holotype)} Body length $10.5 \mathrm{~mm}$.
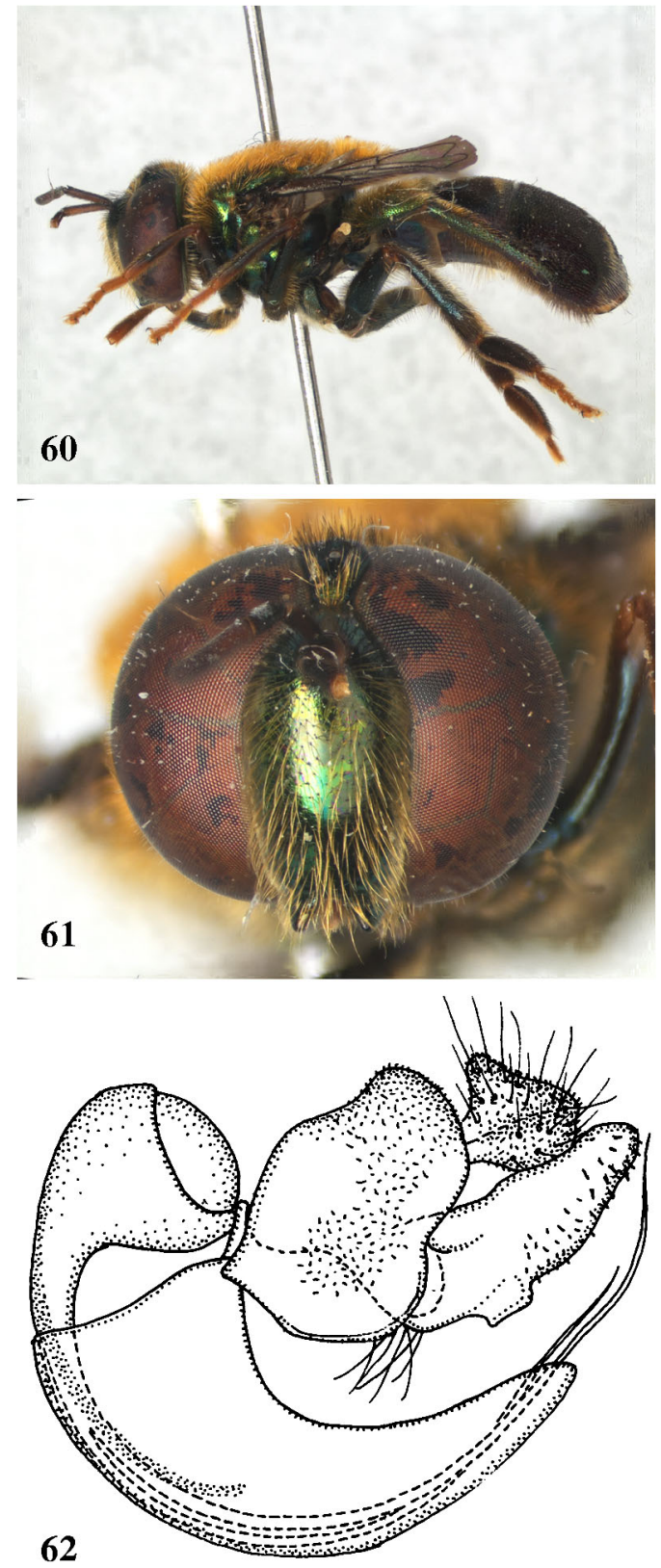

Figs 60-62. Microdon (Microdon) colakriki sp. n., male (holotype). - 60, habitus lateral; 61, head frontal; 62, genitalia lateral.

Head. Dichoptic; eyes separated over a distance approximately equal to width of antennal fossa. Face metallic green, occupying about $1 / 4$ of total head width in frontal view; entirely golden-yellow pilose. Oral margin laterally produced, anteriorly notched. Antennal fossa about as wide as high. Frons metallic green; black pilose. Vertex metallic green; black pi- 
lose medially, yellow pilose anteriorly and posteriorly. Occiput in lateral view narrow, dorsally slightly wider than ventrally; metallic green; with long, posteriorly orientated yellow pile over entirel length; ventrally also with short, more or less appressed white pile along posterior eye margin. Eye entirely white pilose, with pile about as long as diameter of posterior ocelli. Antenna dark brown; antennal ratio approximately $3: 1: 2.5$; scape and pedicel covered with short, appressed black setae, basoflagellomere bare; basoflagellomere parallel-sided with narrowly rounded apex; arista slender, about twice as long as pedicel.

Thorax. Postpronota, mesoscutum and postalar calli shining metallic green; entirely orange pilose. Scutellum trapezium-shaped; shining metallic green anteriorly, gradually turning into dark yellow posteriorly; entirely orange pilose; with small yellow calcars in posterolateral corners. Pleurae shining metallic green, more blackish ventrally and posteriorly. Anepisternum with anterior and posterior part separated by shallow sulcus; anterior and posterior parts orange pilose, transitional area, including sulcus, bare and shining. Anepimeron entirely orange pilose. Katepisternum orange pilose dorsally and (sparsely) ventrally, widely bare in between. Katatergum uniformly covered with long black microtrichia. Anatergum short black microtrichose. Other pleurae bare. Calypter and halter yellow.

Wing - Hyaline; microtrichose, except bare on 1st costal cell, basal $1 / 2$ of 2 nd costal cell, basally on cell $\mathrm{r} 1$ along vein RS, on large parts of cell $r$ except for microtrichia along vena spuria, on basal $1 / 3$ of cell $\mathrm{r} 4+5$, on posterior $1 / 2$ of cell bm, on basal $1 / 6$ of cell $\mathrm{dm}$, along anterior and posterior margins of cell cup, on basomedian 3/4 of alula.

Legs - Coxae and trochanters dark; yellow pilose. Femora blackish; tibiae blackish with narrowly yellow bases and apices; front- and mid-tarsi yellow, hind tarsus with first tarsomere black and other tarsomeres yellow. Legs yellow pilose, except certain anterior and ventral parts of femora with black pile and hind basotarsomere dorsally black pilose.

Abdomen. Tergites 1 and 2 entirely metallic green; yellow pilose. Tergite 3 dull black, except metallic green along anterior, posterior and lateral margins; black pilose, except yellow pilose on metallic green parts. Tergite 4 metallic brownish green; black pilose, except yellow pilose in anterolateral corners and on posterior $1 / 3$. Sternites metallic bluish green; yellow pilose. Genitalia as in Fig. 62.

\section{Etymology}

The specific epithet (noun in apposition) is derived from the name of the type locality, 'Colakreek', the Dutch name for a recreational area near Zanderij,
Surinam. Translated into Sranangtongo, the second language of Surinam, the name is 'Colakriki'.

\section{Notes}

Prior to capture, the holotype was observed sitting on a sunlit leaf of a shrub along a forest path.

\section{Microdon (Microdon) rufiventris (Rondani)}

Figs 6-8, 63, 64

Aphritis rufiventris Rondani, 1848: 73. Holotype: Brazil. (MIZUN). [not examined]

Notes. Albeit short, Rondani's (1891) description of Aphritis rufiventris entirely fits the specimens from Surinam. The type could not be examined, but as there is no other described Neotropical species with the same characters, the specimens from Surinam are identified as this species. Van Doesburg (1962) records this species from Guyana, but the source of
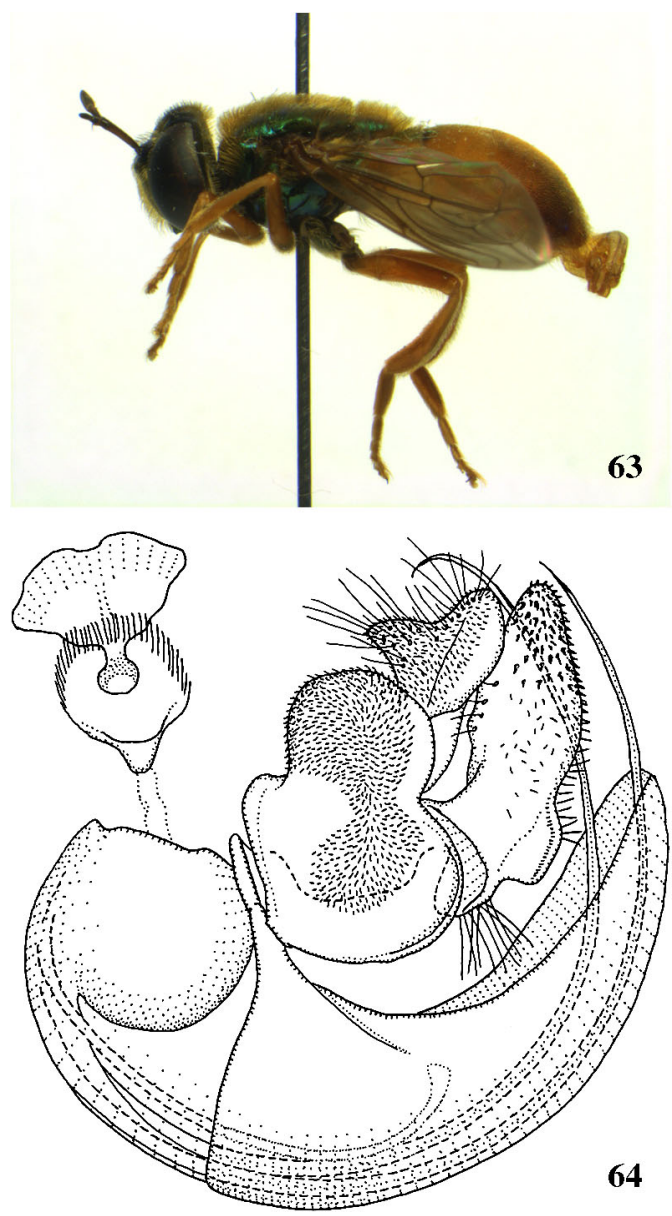

Figs 63, 64. Microdon (Microdon) rufiventris male. - 63, habitus lateral; 64, genitalia lateral. 
that record is unclear. As there are no other records known of this species, some additionally studied specimens from Brazil are also listed below, and a diagnosis of the available material is given. The male genitalia are figured in Fig. 64.

This species seems to be relatively common in Surinam, for within a couple of months nine specimens were found on five different localities. These localities are situated in all three main regions of Surinam: the coastal region, the savanna region and the interior. Remarkably, the species has not been found by P.H. van Doesburg Jr. during the years 19571963 (Van Doesburg 1962, 1966).

The species was found on sunny spots along borders and paths in primary and secondary tropical forest. On three occasions (Brownsberg and Fungu Island), males have been observed displaying territorial behaviour. The males were sitting on sunlit leaves of shrubs and trees along forest paths and forest borders, at a height of 1 to 3 meter. They did not hover, but every once in a while they flew off, in pursuit of some passing insect, after which they returned to take position on the leaves again. At one of the sites (Brownsberg), four males were seen doing this from the leaves of the same shrub, on which they sat at mutual distances of about half a meter. They often flew off at the same time. Females have only been collected in Malaise traps.

In overall colouration and size, the species shows a remarkable similarity to certain night-active bees of the genus Megalopta Smith, 1853 (Hymenoptera: Apoidea: Halictidae), which are common in Surinam. These bees too have a metallic green head and thorax (including propodeum), an orange abdomen and orange legs. At present there are no indications as to whether this similarity is coincidental or some case of mimicry.

New records. Brownsberg, Forest trail to Witti Kreek, 5.ii.2006, leg. M. Reemer, $40^{x}$ (3 RMNH, 1 MZH); Raleigh Falls, Fungu Island, 15.ii.2006, leg. M. Reemer, $2 \sigma^{7}$; Peperpot, Malaise trap, 29.iii6.iv.2006, leg. M. Reemer, $10^{7}$; Perica, Malaise trap, 15-29.x.1997, leg. B. De Dijn, 1 o; Colakreek, Malaise trap, 15-28.iv.2006, leg. M. Reemer, 1 \%.

Additionally studied specimens. BRAZIL: Mato Grosso, Cuyaba, 1 o' (RMNH); Minas Gerais: Belo Horizonte, 800 m, Estação Ecológica, UFMG campus, clear trail $60 \mathrm{~m}$ in from road near swamp, Malaise trap 5-12.vii.1993, leg. S.D. Gaimari, 1 ㅇ (coll. M. Hauser, Sacramento).

\section{Diagnosis}

Body length male 11.5-12.5 ( $\mathrm{n}=7)$, female: $12 \mathrm{~mm}$ $(n=3)$. The largely orange colouration of the abdomen and the entirely orange legs, in combination with the metallic green head and thorax, set
Microdon rufiventris apart from all other known Neotropical Microdon-species. In the last published key to Neotropical Microdon-species (Curran 1941), specimens of this species run to $M$. caesar Curran, 1940 or M. virgo Curran, 1940, depending on the colour of the scutellum. Both of these species, however, have an entirely dark coloured abodomen and at least partially metallic green legs (Curran 1940, and examination of holotypes in coll. AMNH). The genitalia of $M$. rufiventris are very similar to those of $M$. aureopilis Marinoni, 2003 and M. mourei Thompson, 2003. In both of these species the abdomen is entirely metallic green to blue and the legs are at least partially dark (Marinoni \& Thompson 2003).

Notes on variation. The male from Raleigh Falls $\mathrm{Na}-$ tional Park, Surinam (see Additionally studied specimens) is slightly different in colouration from the other specimens from Surinam (Fig. 8). In this specimen, the dark, metallic colouration on tergite 2 is more extensive, tergite 4 is largely dark and metallicly shining, and the mesoscutum and scutellum have a more bluish shine rather than greenish. No other differences could be found in external morphology and genitalia. In the male from Mato Grosso, Brazil the tergites are similarly darkened as the abberant male from Surinam, but the mesoscutum and scutellum are metallic green.

The female from Minas Gerais, Brazil differs from the specimens from Surinam in the scutellum, which is yellow in ground colour when viewed under certain angles. When viewed under different angles, however, it has a clear metallic green shine, like the other specimens.

\section{Microdon (Microdon) virgo Curran} Figs 9, 65

Microdon virgo Curran, 1940: 7. Holotype ơ : Brazil, Nova Teutonia. (AMNH). [examined]

Notes. The specimen from Surinam was compared with the holotype. The specimens are very similar in morphology and colouration, but the following differences were noted: face with yellow pile (white in holotype), wing veins dark (mostly yellowish in holotype), pile on tergite 2 yellow (white in holotype). The taxonomic relevance of these colour differences can only be assessed by studying a large number of specimens from a range of localities. Until such a study has been done, the specimen from Surinam is considered to belong to $M$. virgo.

From related described species (see diagnosis under M. colakriki sp. n.), M. virgo can be distinguished by the combination of the following characters: legs yellow except basal half of femora dark, abdomen entirely shining metallic and entirely yellow to white 


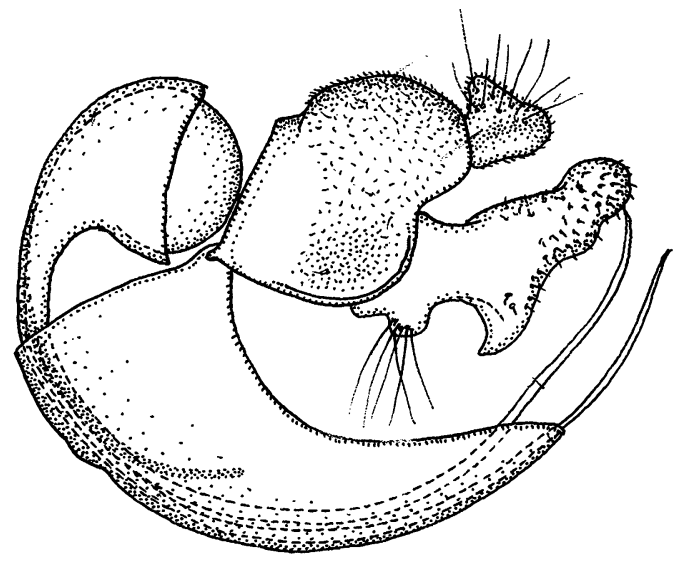

Fig. 65. Microdon (Microdon) virgo male, genitalia lateral.

pilose. The genitalia of the specimen from Surinam are figured in Fig. 65.

The specimen from Surinam was observed sitting on a sunlit leaf of a shrub along a forest path.

New records. Brownsberg, 4.iii.2006, leg. M. Reemer, $10^{7}$.

\section{Peradon Reemer, 2013}

The Neotropical genus Peradon, containing 24 described species, is divided by Reemer \& Ståhls (2013a) into three species groups: bidens-group, flavofascium-group and trivittatum-group. These are merely pragmatic groups for facilitating identification, they are probably not monophyletic. All three groups are represented in Surinam; the flavofascium and trivittatum-group with only one species each $(P$. flavofascium (Curran) and P. trivittatum (Curran), respectively), the bidens-group with 10 species. Of these, two are described here as new, and three unnamed taxa may also represent undescribed species. No information on the larval biology is available for any Peradon species (Reemer 2013a).

\section{Peradon angustiventris (Macquart)}

Fig. 21

Aphritis angustiventris Macquart, 1855: 105. Holotype $\sigma^{7}$ : Guyana (OUMNH). [examined]

Not Microdon angustiventris (Macquart) of Van Doesburg (1962: 12, 1966: 79), misidentification of P. luridescens (Walker).

Microdon angustus (Macquart) of Van Doesburg (1966: 79), misidentification.

Notes. The specimens from Surinam were compared with the holotype of $M$. angustiventris (Macquart), with which they were found to be conspecific. The specimen from Nassau Mountains as recorded by
Van Doesburg (1962) is here considered to belong to $M$. luridescens (Walker). The specimens from Republiek and Zanderij, referred to as Microdon angustus (Macquart) by Van Doesburg (1966), are reidentified as $M$. angustiventris (Macquart). Both localities are in the savannah region of Surinam (district Para), just like the recently collected specimens from Colakreek.

Studied type specimens. HOLOTYPE. Male. Label 1 (small, round, red-bordered): "Holo- / type"; label 2: "A. angustiventris / Ex coll. Bigot"; label 3: "Aphritis / angustiventris / [male sign] Macq.". [OUMNH] Previous records. Republiek, 30.v.1963, 1 ơ; Zanderij, 11.v.1963, 1 o.

New records. Colakreek, 9.iii.2006, $1 \sigma^{7}$; Colakreek, 30.iii.2006, $1 \mathrm{o}^{\prime}$.

\section{Peradon angustus (Macquart)}

Fig. 22

Aphritis angustus Macquart, 1846: 250. Type locality: Cayenne (type lost, see notes and neotype designation).

Not Aphritis angustus Macquart, 1848: 198.

Not Microdon angustus (Macquart) of Van Doesburg (1962: 12, 1966: 79).

Notes. Confusingly, the name Aphritis angustus had been given to two different species by Macquart (1846, 1848), a homonymy already discovered by Lynch Arribálzaga (1891). Aphritis angustus Macquart, 1848 is now considered a synonym of Microdon macquartii Lynch Arribálzaga, 1891, a Neotropical species of Microdon subgenus Microdon (Thompson et al. 1976, Reemer \& Ståhls 2013a).

The type of Aphritis angustus Macquart, 1846 could not be found in the MNHN-collection and is not registered in its type database either (pers. comm. C. Daugeron). It is also not present in the OUMNH-collection, where many other Macquarttypes are deposited (pers. comm. Z. Simmons). Macquart (1846) stated that the specimen on which he based the description is in the collection of $\mathrm{M}$. Spinola. Part of this collection is now housed in the MRSN (Torino), while the Diptera are said to be in the DCDS (Pisa). Enquiry at these institutions did not result in finding the type of this species. Therefore, the type is considered lost.

The specimens from Surinam are considered to belong to $M$. angustus Macquart, 1846 based on the following characters (as translated from the original description): wing with yellow base and brownish apex; abdomen red, turning brown towards apex, with a black dorsal vitta ['bande'] on the third and fourth segment. The 'bande' referred to in the description is here interpreted as vitta, as Macquart uses the word in singular, as if he describes one mark that runs over two tergites. If he would have meant that 
both the third and fourth tergite carry a black fascia, he would have used the plural ('bandes'). Besides, transverse abdominal fasciae are otherwise unknown among related species also belonging to the bidensgroup of Peradon.

There are several species which are closely related to $M$. angustus Macquart, 1846 and their descriptions do not always allow straightforward indentification. This has caused some confusion in previous publications. For instance, Van Doesburg (1962, 1966) used this name for the species that is treated as M. luridescens (Walker) in the present paper. In order to limit future confusion concerning this species group name, a neotype is designated here (see Studied type specimens).

Microdon angustus Macquart differs from $M$. bidens (Fabricius) by its partly yellow wings and partly black abdomen (entirely red in $M$. bidens). From $M$. angustiventris (Macquart) it differs by the more contrasting wing pattern and the partly black abdomen (entirely orange in $M$. angustiventris). From $M$. luridescens (Walker) it differs by the more contrasting wing pattern and the partly reddish tergites 3 and 4 (entirely blackish brown in $M$. luridescens). From M. flavipennis Curran, 1925 it differs by the partly reddish tergites 3 and 4 (entirely blackish in M. flavipennis).

Studied type specimens. NEOTYPE (new designation, see notes). Female. Label 1: "SURINAME. Commewijne, / Mopentibo, near Meerzorg / $05^{\circ} 47^{\prime} 57^{\prime \prime} \mathrm{N}-55^{\circ} 07^{\prime} 05^{\prime \prime} \mathrm{W} /$ 19.iv.2006. M. Reemer" (RMNH).

New records. Mopentibo, 19.iv.2006, 1 우 (neotype, see above); Peperpot, 21-28.iii.2006, 1 ㅇ.

\section{Peradon bidens (Fabricius)}

Fig. 25

Mulio bidens Fabricius, 1805: 185. Holotype $\sigma^{7}$ : South America (ZMUC). [examined]

Ceratophya bicolor Walker, 1857.

Microdon bidens (Fabricius): Van Doesburg (1962: 12, 1966: 79).

Notes. The specimens from Surinam were found to be conspecific with the holotype of Mulio bidens Fabricius, as well as with the type of Ceratophya bicolor Walker, which is here considered to be a junior synonym.

This species was found on sunny spots among or along shrub vegetation, like forest borders and forest paths. Males were observed displaying territorial behaviour from leaves low above the ground, flying to and fro, sometimes hovering for short periods.

Studied type specimens. HOLOTYPE Mulio bidens Fabricius. Male. Label 1 (red): "TYPE"; label 2: "M: bidens / 'Am:mer:Schmid" (ZMUC).
HOLOTYPE Ceratophya bicolor Walker. Female. Label 1 (round, red-bordered): "Holo- / type"; label 2 (round, green-bordered): "Type"; label 3: "Para"; label 4: "Ceratophya / bicolor / Wlk."; label 5: "bicolor Wlk" (BMNH).

Previous records. Paramaribo, 15.vii.1944, leg. D.C. Geijskes, 1 † (NZCS); Paramaribo, 28.i.1960, leg. P.H. van Doesburg Jr., 1 q (RMNH).

New records. Peperpot, 4.iii.2006, $10^{7}$ (MZH); Zanderij, 16.iii.2006, 1 ơ; Peperpot, 14-21.iii.2006, $10^{\prime}$.

\section{Peradon flavofascium (Curran)}

Figs 32, 33

Microdon flavofascium Curran, 1925: 346. Holotype $\sigma^{7}$ : Brazil (CU). [examined]

Microdon flavofascium Curran: Van Doesburg (1966: 80).

Notes. In the specimens from Surinam the yellow wing fascia is less conspicuous than in the holotype. Otherwise the specimens are very similar, also in male genitalia.

The female from Colakreek was observed flying low above leaf litter in shady conditions in the forest. Studied type specimens. HOLOTYPE. Male. Label 1: "Lassance, Minas Ger's BRAZIL 9-19 Nov. 1919"; label 2 (red): "Type Microdon flavofasciatum Curran"; label 3 (red): "Holotype Cornell U. No. 1737"; label 4: "Microdon flavofascium Curran Det. C.H. Curran".

Previous records. Raleigh Falls, 16.vii.1963, leg. P.H. van Doesburg Jr., 1 o' (RMNH).

New records. Brownsberg, 20.vii-3.viii.2001, leg. N. Grol \& N. Marseille, 1 † (RMNH); Colakreek, 1.iii.2006, 1 ㅇ.

\section{Peradon langi (Curran)}

Fig. 26

Microdon langi Curran, 1925: 341. Holotype $\sigma^{2}$ : Guyana $(\mathrm{AMNH})$. [examined]

Notes. The specimens from Surinam agree well with the type specimen, as well as with the original description of Curran (1925). This species seems to differ from $M$. bidens only in the colouration of the abdomen. In all other characters, including wing colouration, microtrichia and male genitalia, $M$. bidens and $M$. langi are identical. The possibility that these taxa are colour morphs of the same species should be considered. The specimens were found in similar habitat as those of $M$. bidens.

Studied type specimens. HOLOTYPE (AMNH). Male. Label 1: "Kumakusa, Brit. Guiana, IX-1922. H. Lang"; label 2 (red label): "Type Microdon langi Curran"; label 3: "C.H. Curran collection, Acc. 
31144"; label 4: "Microdon langi Curran, Det. C.H. Curran".

New records. Colakreek, 30.iii.2006, $1 \sigma^{\mathrm{T}}$; Mopentibo, 19.iv.2006, $10^{7}$.

\section{Peradon luridescens (Walker)}

Fig. 23

Ceratophya luridescens Walker, 1857: 151. Holotype o: "Valley of Amazon" (BMNH). [examined]

Microdon angustus Macquart, 1846 of Van Doesburg (1962: 12).

Not Microdon angustus Macquart of Van Doesburg (1966: 79), misidentification of Peradon angustiventris (Macquart, 1855).

Notes. All three localities on which this species was found (Brownsberg, Lely, Nassau) are plateaus with an altitude of about 500 meters, which are renowned for bauxite mining activities. The males collected in 2006 were found in and along forest on leaves along roadsides and paths.

Studied type specimens. HOLOTYPE. Female. Label 1 (round, red-bordered): "Holo- / type"; label 2 (round, green-bordered): "Type"; label 3: "Amaz";
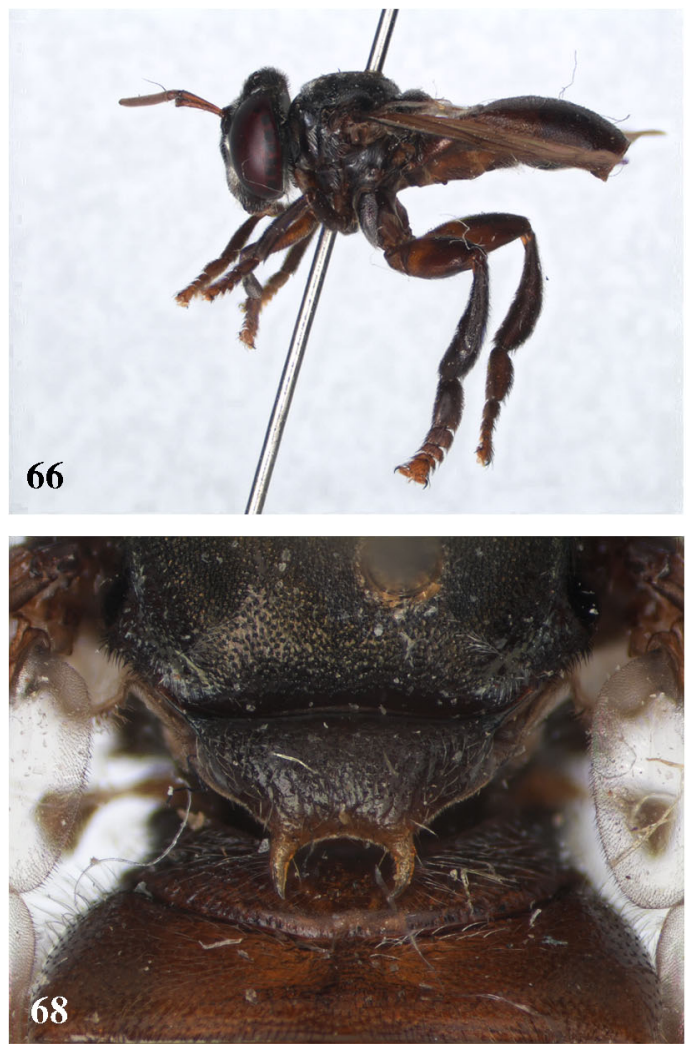

label 4: "luridescens Wlkr"; label 5: "Ceratophya / luridescens. / Wlk.”. [BMNH]

Previous records. Nassau Mountains, 4.iii.1949, leg. D.C. Geijskes, $1 \sigma^{7}$ (RMNH).

New records. Brownsberg, 14.ix.1938, leg. D.C. Geijskes, 1 q (RMNH); Lely, 30.x.1979, leg. G.F. Mees, $1 \sigma^{7}$ (RMNH); Nason, 19.iii.2006, $2 \sigma^{7}$; 23.iii.2006, Nassau Mts., $2 \sigma^{7}$ (1 in MZH, 1 RMNH); 3 males, Nassau Mts., 24.iii.2009, 3 o".

\section{Peradon satyricus sp. $\mathbf{n}$.}

Figs 29, 66-69

Type specimens. Holotype $\sigma^{7}$. Label 1: "SURINAME. Brownsberg / $04^{\circ} 56^{\prime} 45^{\prime \prime} \mathrm{N}-55^{\circ} 10^{\prime} 59^{\prime \prime} \mathrm{W} /$ 2.iv.2006. M. Reemer" (RMNH).

Paratype. $1 \sigma^{x}$, French Guyana, Montagne de Kaw, Piste Lallane, $04^{\circ} 34^{\prime} \mathrm{N}-52^{\circ} 13^{\prime} \mathrm{W}$, leg. C.M.T. Raper $\&$ A. Nelid, "On flowers" (RMNH).

\section{Diagnosis}

A compact, blackish species with stout legs, resembling a Trigona bee. It belongs to the bidens species group because of the unconstricted abdomen and the

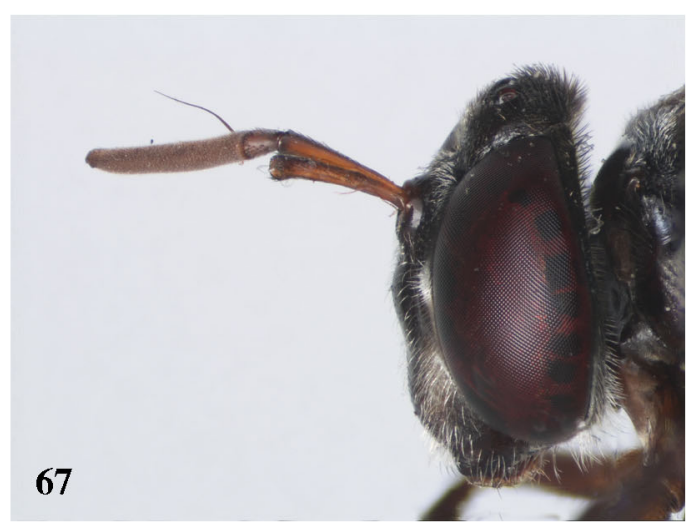

69

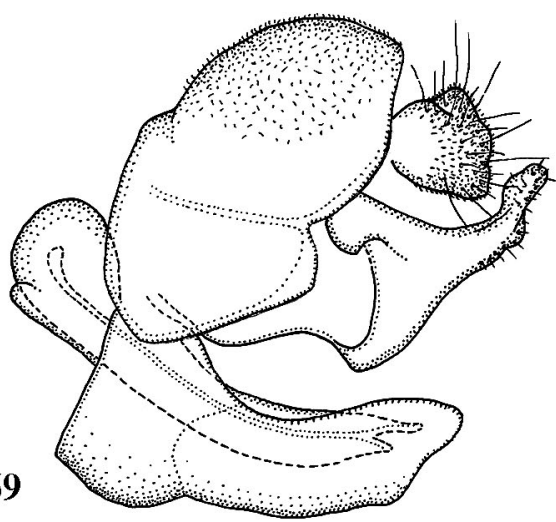

Figs 66-69. Peradon satyricus sp. n. male (holotype). - 66, habitus lateral; 67, head lateral; 68, scutellum dorsal; 69, genitalia lateral. 
absence of golden pile on the tergites. The species is distinguished from other species of this group by the obviously produced vertex.

\section{Description of adult male (based on holotype) Body length $8 \mathrm{~mm}$.}

Head. Dichoptic. Face occupying about $2 / 5$ of total head width in frontal view; black with yellow lateral vittae; entirely white pilose; white pollinose on yellow lateral vittae; eye margins converging at level of frons, with smallest distance approximately equal to twice the width of antennal fossa. Gena black. Oral margin laterally produced; black. Antennal fossa about as wide as high. Frons black; black pilose. Vertex produced; shining black; black pilose, except white pilose anteriorly. Ocellar triangle not elevated; frontal angle about $80^{\circ}$. Occiput narrow; black; black pilose dorsally, white pilose ventrally. Eye bare. Antenna brown; antennal ratio approximately 4:1:6; basoflagellomere parallel-sided with rounded apex, with small sensory pit located at about $1 / 2$ its length; arista slender, about 3/4 length of basoflagellomere.

Thorax. Mesoscutum black; black pilose, except for narrow, medially interrupted fasciae of white pile along anterior and posterior margin and along transverse suture. Postpronotum black; black pilose. Postalar callus black; black pilose. Scutellum with two strong, curved apical calcars of $1 / 2$ of length of scutellum; black, except yellowish apically; white pilose. Pleurae blackish. Anepisternum with anterior and posterior part separated by clear sulcus; anterior part black pilose, posterior part white pilose, with bare area in between. Anterior anepimeron entirely white pilose. Katepisternum white pilose dorsally, bare ventrally. Katatergum with long black microtrichia, arranged in oblique rows. Anatergum short pale microtrichose. Other pleurae bare. Calypter greyish yellow. Halter brown.

Wing - Hyaline; microtrichose, except bare on 1st costal cell, basal $1 / 6$ of 2 nd costal cell, basally on cell r1 along vein RS, basal 4/5 of cell $r$, on basal $1 / 4$ and narrowly along anterior margin of cell bm, on basal $1 / 4$ of cell cup.

Legs - Blackish brown, but paler brown on basal half of femora and apical tarsomeres; black pilose, except tibiae white pilose dorsally on basal 3/4. Hind femur and tibia strongly widened. Coxae and trochanters brown; black pilose, except hind coxa with white pile apically.

Abdomen. Tergites blackish brown. Tergites 1 and 2 white pilose. Tergites 3 and 4 black pilose, except white pilose laterally. Sternites brown; sternite 1 bare; sternites 2-4 white pilose. Genitalia as in Fig. 69.

Female. Unknown.

\section{Etymology}

The name satyricus is an adjective derived from the Greek word 'satyr', a wood-dwelling, horn-bearing deity in Greek mythology. This name was chosen because the species was collected in a forest and because of the strong, curved scutellar calcars resemble the horns of a satyr.

\section{Notes on variation}

In the paratype the antenna, legs and abdomen are of a paler brown colour than in the holotype. The scutellar calcars are about $1 / 3$ of the length of the scutellum.

\section{Peradon sciarus sp. $\mathbf{n}$.}

Figs 70-72

Type specimens. Holotype $\sigma^{7}$. Label 1: "SURINAME. Awarradam / along Gran Rio river. / $03^{\circ} 50^{\prime} 41^{\prime \prime} \mathrm{N}-55^{\circ} 36^{\prime} 48^{\prime \prime} \mathrm{W} /$ 13.iv.2006 / M. Reemer" (RMNH).

Paratypes. $1 \sigma^{7}$, same locality and date as holotype $(\mathrm{RMNH}) ; 10$, French Guyana, Roura, Kaw road, PK 37, Relais Patawa, $04^{\circ} 32^{\prime} 42^{\prime \prime} \mathrm{N}-52^{\circ} 09^{\prime} 09^{\prime \prime} \mathrm{W}$, xi.2008 (Malaise trap), leg. J.A. Cerda (RMNH).

\section{Diagnosis}

A slender, black species with infuscated wings. It belongs to the bidens species group because of the unconstricted abdomen and the absence of golden pile on the tergites. This species is similar to Peradon bispina (Hull, 1943), but that species has a small, elongate yellow mark in wing cell $r 4+5$ along the apical part of the vena spuria, while in P. sciarus sp. $\mathrm{n}$. the wing is entirely dusky.

\section{Description of adult male (based on holotype) Body length $10 \mathrm{~mm}$.}

Head. Dichoptic. Face occupying about $1 / 3$ of total head width in frontal view; dark yellow with short blackish lines lateroventrad of antennal fossa; yellow pilose with very narrow bare median stripe; narrowly white pollinose laterally; eye margins converging at level of frons, with smallest distance approximately 1.5 times the width of the antennal fossa. Gena black. Oral margin laterally produced; black. Antennal fossa about as wide as high. Frons black; black pilose. Vertex black; mixed black and yellow pilose. Ocellar triangle not elevated; frontal angle about $60^{\circ}$. Occiput narrow; black; yellow pilose dorsally, white pilose ventrally. Eye bare. Antenna brown; antennal ratio approximately 4:1:6; basoflagellomere parallelsided with rounded apex, with small sensory pit located just basal of $1 / 2$ its length, situated in a long groove that reaches from ventral of the base of the 

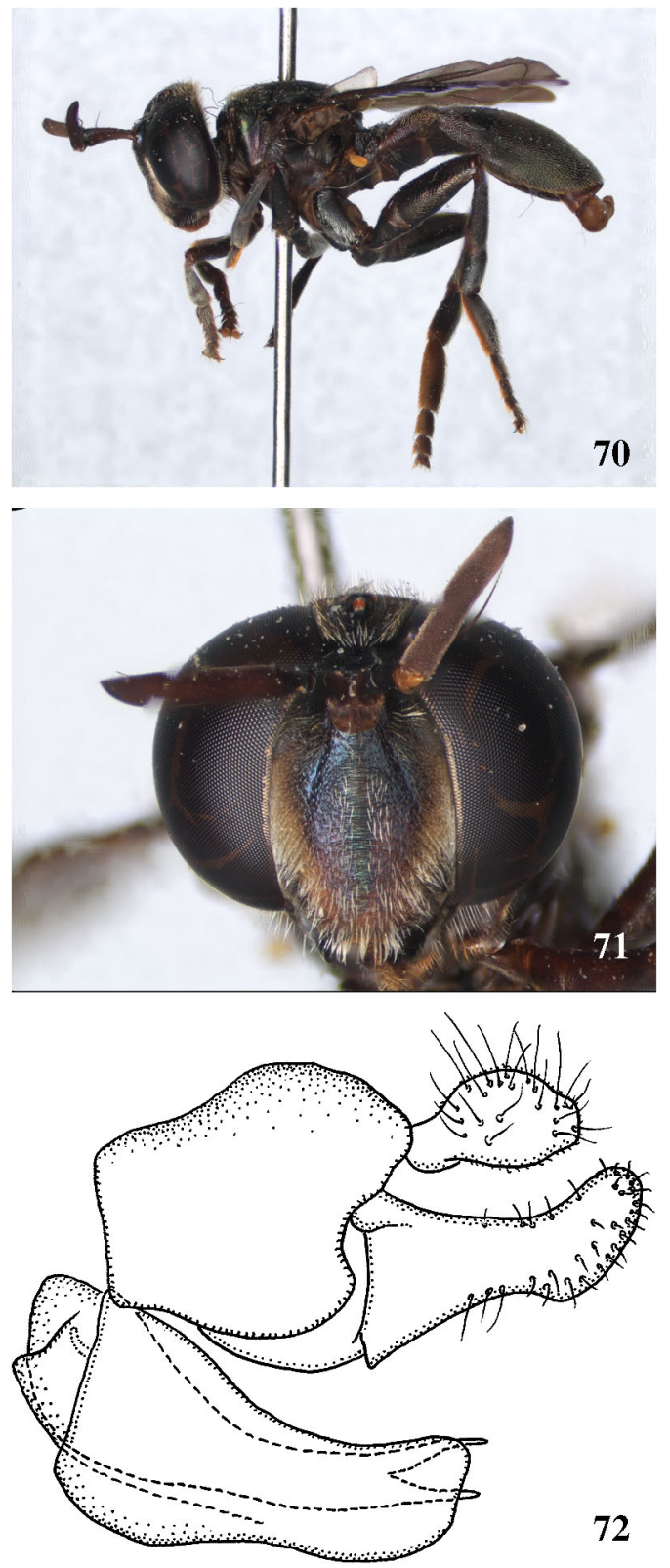

Figs 70-72. Peradon sciarus sp. n. male. -70 , habitus lateral (holotype); 71, head frontal (holotype); 72, genitalia lateral (paratype).

arista almost to the apex; arista slender, about $3 / 4$ length of basoflagellomere.

Thorax. Mesoscutum black, with faint metallic green hues along margins; black pilose, except for narrow, inconspicuous fasciae of golden yellow pile along anterior and posterior margin and a medially interrupted one along transverse suture. Postpronotum black; yellow pilose. Postalar callus black; golden yellow pilose. Scutellum with two yellow apical calcars of 1/4 of length of scutellum; black with faint metallic green hues, except narrowly yellowish along apical margin; yellow pilose. Pleura blackish. Anepisternum with anterior and posterior part separated by clear sulcus; anterior and posterior part yellow pilose, with bare area in between. Anterior anepimeron entirely white pilose. Katepisternum white pilose dorsally, bare ventrally. Katatergum with long black microtrichia, arranged in oblique rows. Anatergum short pale microtrichose. Other pleurae bare. Calypter greyish. Halter yellow.

Wing - greyish, mostly so on anterior half; microtrichose, except bare on 1st costal cell, on cell $r$ except microtrichose along vena spuria, narrowly along anterior margin of cell bm, basomedially on alula.

Legs - Blackish brown, with base of tibiae slightly paler; yellowish to white pilose, except tibiae ventrally black pilose. Coxae and trochanters black; white pilose.

Abdomen. Tergites blackish brown, with faint metallic hues. Tergites yellowish to white pilose, except tergite 3 black pilose medially. Sternites blackish brown; sternite 1 bare; sternites 2-4 white pilose. Genitalia as in Fig. 72.

Variation. In the paratype from Surinam, the anterolateral corners of tergite 2 are faintly yelowish brown. Female. Unknown.

\section{Etymology}

The adjective sciarus (Gr.: of shade) was chosen to name this species because in Surinam the flies were found in shady conditions, and also because of its dusky appearance.

\section{Ecology}

Both specimens from Surinam were found flying low above the ground on a shady place along a path through secondary forest.

\section{Peradon trivittatum (Curran)}

Fig. 34

Microdon trivittatum Curran, 1925: 344 . Holotype ơ : Guyana

(Kartabo) (AMNH). [examined]

Microdon trivittatum Curran: Van Doesburg (1966: 83).

Notes. The specimens from Surinam were compared with the holotype and found to be conspecific. The genitalia of the male from Brownsberg are figured by Reemer \& Ståhls (2013a).

This species is very similar to $M$. trilinea Hull, but in that species tergite 2 is parallel-sided, clearly flatter than in trivittatum and about as wide as tergite 3 . Microdon fenestratus Hull, 1943 is also similar, but larger $(17 \mathrm{~mm})$, with pile on scutellum yellow and 
erect instead of golden and appressed (Hull 1943). Microdon aureoscutum Hull, 1943 is another similar species, but in that species the mesonotum is without golden pilose lateral and anterior margins.

On 3.iv.2006, in Brownsberg nature reserve, a male was observed displaying territorial behaviour near a fallen tree trunk in a forest clearing, resting on leaves on the ground and occasionally flying over short distances.

Previous records. Carolinakreek, 30.iv.1962, leg. P.H. van Doesburg Jr., $10^{\top}$.

New records. Raleigh Falls, 11.vii.1963, leg. P.H. van Doesburg, 1 ơ; Perica, 11-25.vi.1997, leg. B. De Dijn, 1 \%; Brownsberg, 3.iv.2006, $1 \sigma^{7}$.

\section{Peradon SUR-17a}

Figs 29, 73

Notes. This specimen is similar in colouration to Peradon normalis (Curran), but it measures only $10 \mathrm{~mm}$, while $P$. normalis measures $18 \mathrm{~mm}$ (Curran 1925). It is also similar to Peradon SUR-18 (Microdon normalis sensu Van Doesburg 1962), and to Peradon SUR$17 \mathrm{~b}$. For differences see notes under those species. The identity of this specimen is left unresolved.

New records. Brownsberg, 2.iv.2006, 1 o .

\section{Peradon SUR-17b}

Fig. 30

Notes. This specimen is exactly similar to Microdon SUR-17b in morphology and colouration, except for the very different (almost inverse) colour pattern on the wing. A puzzling dimension to this similarity is added by the fact that both female specimens of these two species were captured within a few minutes on exactly the same locality. Perhaps the specimens are colour forms of the same species. This problem can only be solved under availability of a larger number of specimens.

New records. Brownsberg, 2.iv.2006, 1 ․

\section{Peradon SUR-18}

Figs 31, 74

Microdon normalis Curran, 1925 of Van Doesburg (1962: 13, 1966: 83), misidentification.

Notes. This male specimen was identified by Van Doesburg $(1962,1966)$ as $P$. normalis (Curran), to which it is similar in wing colouration. However, it measures only $11 \mathrm{~mm}$, while the female holotype $P$. normalis measures $18 \mathrm{~mm}$ (Curran 1925). This size difference could be a matter of sexual dimorphism, but it is an unusually large difference for species of the bidens-group. Other differences with $P$. normalis are (character state of the holotype of $P$. normalis in
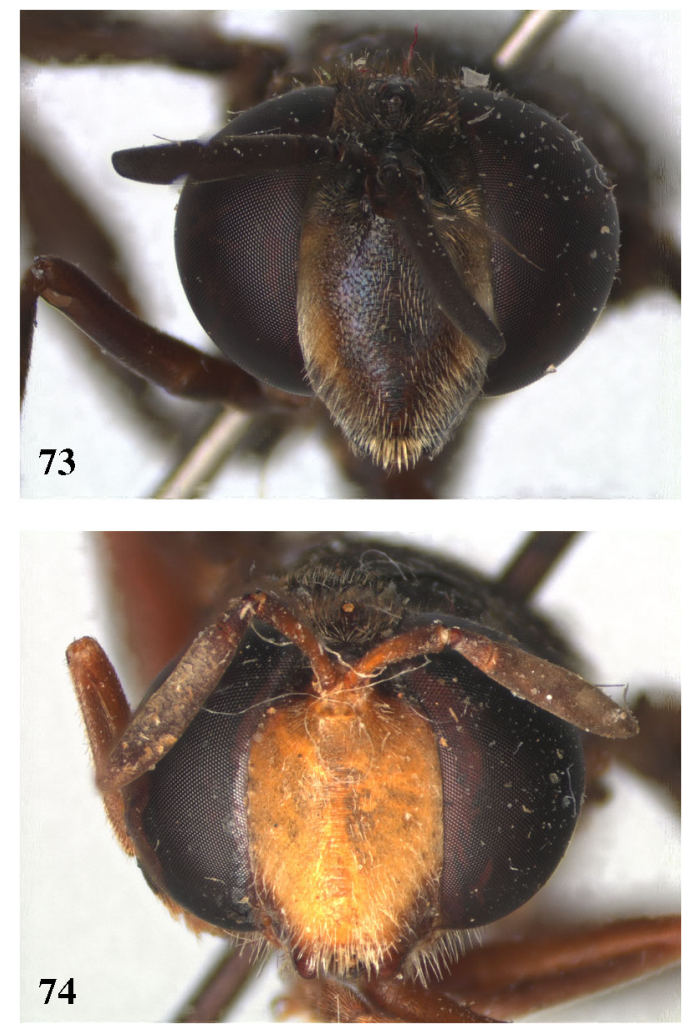

Figs 73, 74. Peradon, head frontal. - 73, P. SUR-17a female; 74, $P$. SUR-18 male.

parentheses): face entirely yellow (brown, the sides rather narrowly reddish), yellow wing spot reaching from apical $2 / 3$ of cell $\mathrm{r} 4+5$ to anterior wing margin (confined to apical $1 / 2$ of cell r $4+5$ ). Peradon SUR-18 differs from $P$. SUR-17a in the same characters, except that they hardly differ in body length $(10 \mathrm{~mm}$ in $P$. SUR-17a). It is also similar to Peradon SUR-17b, but clearly differs in wing colouration (but see notes under that species!). The taxonomic importance of the noted differences between these 'species' can only be assessed when more specimens are available.

Previous records. Surinam (date and collector unknown), $10^{2}$.

\section{Pseudomicrodon Hull, 1937}

The Neotropical genus Pseudomicrodon presently includes 15 described species. Several others are awaiting description in entomological collections, and the genus is subject to a revision by F.C. Thompson (pers. comm.). Three species are known from Surinam, one of which is undescribed. One species of Pseudomicrodon (not known from Surinam) has been 
found in association with ants of the genus Crematogaster (Schmid et al. in press).

\section{Pseudomicrodon batesi (Shannon)}

Figs 35, 75

Microdon batesi Shannon, 1927: 22. Holotype o: Brazil (BMNH). [examined]

Microdon beebei Curran, 1936: 4. Holotype q: Guyana. Syn. n. (AMNH). [examined]

Pseudomicrodon beebei (Curran): Van Doesburg (1966: 87).

Notes. The specimens from Surinam have been compared with the types of Microdon batesi Shannon and $M$. beebei Curran and was found to belong to the same species. In Van Doesburg (1966) the figure legends of this species (p. 89) and Rhopalosyrphus guentheri (Lynch Arribálzaga) (p. 88) were accidentally swapped.

Previous records. Republiek, 30.x.1963, leg. D.C. Geijskes, 1 o; Phedra, 26.x.1964, 1 o and 14.xii. 1964, 1 o', leg. D.C. Geijskes.

\section{Pseudomicrodon nigrispinosus (Shannon)}

Figs 36, 76

Microdon nigrispinosus Shannon, 1927: 21. Syntypes ơ : Brazil, Tefe (BMNH). [examined]

Microdon nigrispinosus Shannon: Van Doesburg 1966: 82.

Notes. The specimen from Surinam, a male, was compared with the syntypes and is considered conspecific.

Previous records. Republiek, 18.iv.1960, $1 \sigma^{7}$, leg. P.H. van Doesburg Jr.

\section{Pseudomicrodon SUR-22}

Fig. 37

Notes. The only known specimen of this species was not mentioned in Van Doesburg's papers. It seems to belong to an undescribed species. However, a species revision of Pseudomicrodon is required to be certain about this, so it is not described here.

New records. Zanderij, 21.viii.1963, leg. J. van der Vecht, 1 o.

\section{Rhoga Walker, 1857}

The Neotropical genus Rhoga includes stingless bee mimicking species, five of which have been described so far.

\section{Rhoga SUR-01}

Fig. 52

Notes. Only five species of Rhoga are described, but several others await description in entomological col-

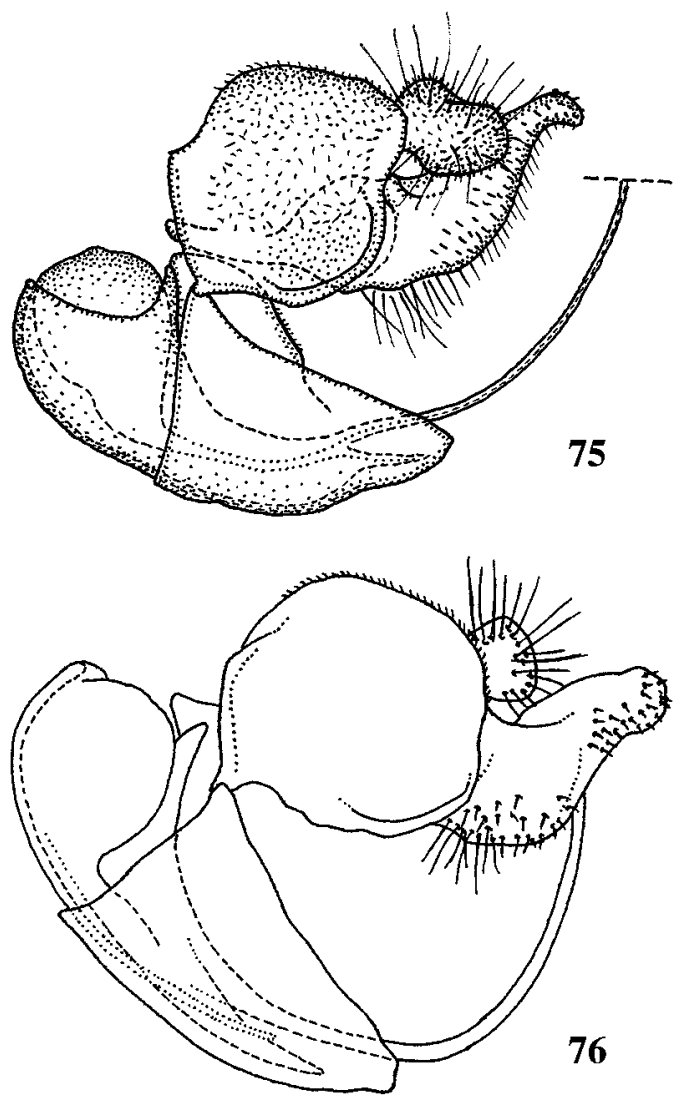

Figs 75, 76. Pseudomicrodon, male genitalia. - 75, $P$. batesi, Phedra 14.xii.1964; 76, P. nigrispinosus, Republiek 18.iv. 1960.

lections. The only known Surinam specimen of this genus resembles Rhoga mellea (Curran, 1940), but a more certain identification cannot be given before a larger number of specimens of various species have been studied in more detail.

New records. Peperpot, 9-17.ii.2006, 1 \%.

\section{Rhopalosyrphus Giglio-Tos, 1891}

The New World genus Rhopalosyrphus contains ten described species, one of which is known from Surinam. Identification of described species can be done using Reemer \& Ståhls (2013a) combined with Thompson (2012).

\section{Rhopalosyrphus guentherii (Lynch Arribálzaga)}

Fig. 38

Holmbergia günterii Lynch Arribálzaga, 1891: 197. Holotype: Argentina (MACN). [not examined] 
Rhopalosyrphus güntheri (Lynch Arribálzaga): Van Doesburg (1966: 88).

Notes. Identification of the only specimen known from Surinam, a female, has been verified using Weems et al. (2003). Rhopalosyrphus guntheri is a widespread species, ranging from Texas and Arizona to Argentina and Brazil (Weems et al. 2003). The photographs of this species and Pseudomicrodon batesi in Van Doesburg (1966) have been interchanged: Fig. 61 depicts $R$. guentherii.

Previous records. Paramaribo, 2.v.1962, 1 \%, leg. P.H. van Doesburg Jr.

\section{Schizoceratomyia Carrera, Lopes \& Lane, 1947}

Schizoceratomyia is one of the Neotropical genera in which the basoflagellomere of the male is bifurcate. Four species are described, two of which are known from Surinam.

\section{Schizoceratomyia barretoi Carrera, Lopes \& Lane}

Fig. 17

Schizoceratomyia barretoi Carrera, Lopes \& Lane, 1947: 473. Holotype $\sigma^{7}$ : Brazil (MZUSP). [examined in USNM]

Schizoceratomyia barretoi Carrera, Lopes \& Lane: Van Doesburg (1966: 92).

Notes. In the two specimens from Surinam the rudimentary arista is slightly longer than in the drawings of Carrera et al. (1947), but otherwise they seem to agree well with $S$. barretoi, also in the genitalia. In some Brazilian specimens (coll. M. Hauser, Sacramento) the frontal ocellus is absent. In the specimen from Surinam it is present, but medially divided into two parts. Study of additional material is needed to assess the taxonomic significance of this character.

Previous records. Zanderij, 8.v.1963, leg. P.H. van Doesburg Jr., $1 \sigma^{\text {T }}$; Zanderij, 11.v.1963, leg. J. van der Vecht, $1 \sigma^{x}$.

\section{Schizoceratomyia flavipes Carrera, Lopes \& Lane}

Fig. 18

Schizoceratomyia flavipes Carrera, Lopes \& Lane, 1947: 247. Holotype $\sigma^{7}$ : Brazil, São Paulo (MZUSP). [examined in USNM]

Notes. The specimens from Surinam are very similar to the holotype of $S$. flavipes Carrera, Lopes \& Lane 1947, also in their genitalia. In the original description by Carrera et al. (1947) the antenna is figured with a rudimentary arista, much shorter than the pedicel. However, both in the holotype and in the specimens from Surinam, the arista is well developed and clearly longer than the pedical. Possibly this character is variable.

New records. Brownsberg (Jeep Trail), 15-29.viii. 2001, leg. N. Grol \& N. Marseillle, $1 \sigma^{7}$; Brownsberg (main camp), 4.iii-1.iv.2006, $3 \sigma^{7}, 2$ \%; Brownsberg (Mazaroni Trail), 4.iii-1.iv.2006, $1 \sigma^{\top}$; Brownsberg, 7-14.ii.2008, leg. A. Gangadin \& K.-D.B. Dijkstra, $20^{7}$.

\section{Stipomorpha Hull, 1945}

Stipomorpha is a Neotropical genus of species which are remarkably good mimics of Trigona-like stingless bees. The 25 described species can be identified using the key in Reemer (2013b). Nine species are known from Surinam.

\section{Stipomorpha goettei (Shannon)}

Fig. 45

Microdon (Ubristes) goettei Shannon, 1927: 19. Lectotype q: Brazil, Ega (BMNH). [examined]

Not Ubristes goettei (Shannon) of Van Doesburg (1966: 85), misidentification of Stipomorpha guianica (Curran).

Notes. Van Doesburg (1966) listed several specimens of $S$. goettei, but these were all found to belong to S. guianica (Curran). The 'real' S. goettei has been found in Surinam only in recent years.

New records. Akintosoela, mapane area, 28.vii.1995, leg. B. De Dijn \& A. Gangadin, $10^{\top}$; Zanderij road to Kraka, 16.iii.2006, 1 q.

\section{Stipomorpha guianica (Curran)}

Figs 46, 47

Microdon guianicus Curran, 1925: 340. Holotype q: Guyana, Bartica (MCZ). [examined]

Not Microdon guianicus Curran of Van Doesburg (1962: 13).

Ubristes goettei (Shannon) of Van Doesburg (1966: 85), misidentification.

Notes. For notes on confusion with $S$. goettei see account of that species. The two male specimens recorded as Microdon guianicus by Van Doesburg (1962) belong to Stipomorpha lanei (Curran), as Van Doesburg (1966) already suspected.

Two males of this species were observed visiting (unidentified) white flowers: Paramaribo Cultuurtuin 7.iii.2006 and Peperpot 28.iii.2006. At the same time, several stingless bees of similar appearance (presumed models for mimicry) were also seen visiting these flowers.

Previous records. Paramaribo Cultuurtuin, 9.iii. 1961, leg P.H. van Doesburg Jr., 1 ơ 1 \%; Paramaribo Cultuurtuin, 23.iv.1963, $1 \sigma^{\top}$; Republiek, 19.x.1963, leg. D.C. Geijskes, 1 o and 5.xi.1963, leg. D.C. 
Geijskes, 1 q; Lelydorp, 5.viii.1963, leg. D.C. Geijskes, $1 \%$ and 31.i.1964, leg. D.C. Geijskes, $1 \%$ and 29.v.1964, leg. D.C. Geijskes, 1 \%; Ma Retraite 2324.viii.1963, leg. D.C. Geijskes, 1 o and 28.ii.1964, leg. D.C. Geijskes, 1 o.

New records. Paramaribo Leiding, 28.i-6.ii.2006, 1 \%; Peperpot, 2-9.ii.2006, 1 \%; Paramaribo Cultuurtuin, 7.iii.2006, $1 \sigma^{7}$ (col. MZH); Peperpot, 2128.iii.2006, 1 \%; Peperpot, 28.iii.2006, $1 \sigma^{7}$; Peperpot, 29.iii-6.iv.2006, 1 o; Peperpot, 6-14.iv.2006, 2 o; Peperpot, 14-20.iv.2006, 2 o; Peperpot, 2027.iv.2004, 1 \%; Perica, 20.viii-3.ix.1997, leg. B. De Dijn, 1 \%; Perica, 10-24.xii.1997, leg. B. De Dijn, 1 ‥

\section{Stipomorpha lacteipennis (Shannon)}

Fig. 49

Microdon (Ubristes) lacteipennis Shannon, 1927: 18. Lectotype $\sigma^{7}$ : Brazil, Amazon (BMNH). [examined]

Ubristes lacteipennis (Shannon): Van Doesburg (1962: 14, 1966: 85).

Previous records. Republiek, 29.ix.1959, leg. P.H. van Doesburg Jr., 1 o 1 \%; Republiek, 5.xi.1963 $10^{\pi}$, 9.xi.1963 1 क, 8.x.19631 क, 5.xi.1963 1 क, leg. D.C. Geijskes; Blakawatra, 13.vi.1963, leg. E. van der Vecht, 10 .

New records. Peperpot, 20-27.iv.2006, 1 q.

\section{Stipomorpha lanei (Curran)}

Fig. 48

Microdon lanei Curran, 1936: 5. Holotype o: Brazil (Sao Paulo) (AMNH). [examined]

Microdon guianicus Curran of Van Doesburg (1962: 12), misidentification.

Microdon lanei Curran: Van Doesburg (1966: 82).

Notes. Van Doesburg (1962) recorded two males of Stipomorpha guianica (Curran) (as Microdon guianicus) from Paramaribo, but Van Doesburg (1966) stated that these possibly belong to Stipomorpha lanei, of which he also recorded a male from Kwatta. This suspicion is here confirmed, based on examination of the specimens.

Previous records. Paramaribo, 9.xii.1957, leg. P.H. van Doesburg Jr., 2 ơ $^{7}$ Kwatta, 8.ii.1964, leg. D.C. Geijskes, 1 \%.

New records. Paramaribo Leiding, 28.i-6.ii.2006, $10^{7}$.

\section{Stipomorpha mackiei (Curran)}

Fig. 40

Microdon mackiei Curran, 1940: 5. Holotype $\sigma^{7}$ : Guyana, Rockstone (AMNH). [examined]
Ubristes mackiei (Curran): Van Doesburg (1966: 85).

Notes. Females of this species can at present not be reliably distinguished from those of $S$. tenuicauda (Curran, 1925) (Reemer 2013b). Occurrence of $S$. mackiei in Surinam is established by examination of the genitalia of the only known male specimen from this country: Charlesburg, 21.i.1964, leg. D.C. Geijskes (year erroneously stated as 1963 by Van Doesburg 1966). The female specimens listed below are only preliminarily assigned to $S$. mackiei.

Previous records. Paramaribo, iv.1950, leg. D.C. Geijskes, 1 ; Charlesburg, 21.i.1963, leg. D.C. Geijskes, $1 \mathrm{O}^{7}$; Raleigh Falls, 12.vii.1963, leg. D.C. Geijskes, 1 \%; Blakawatra, 11.vi.1963, leg. E. van der Vecht, 1 o.

New records. Brownsberg, 21.vi-5.vii.2001, leg. A. Gangadin, 1 \%; Oost-Westverbinding 70 km E Paramaribo, 21.x.1995, leg. B. De Dijn, 1 q; Peperpot, 24.ii-7.iii.2006, 1 \%; Peperpot, 29.iii-6.iv.2006, 1 \%; Peperpot, 6-14.iv.2006, 1 \%; Perica, 6-20.viii.1997, leg. B. De Dijn, 2 \%; Perica, 21.i-4.ii.1998, leg. B. De Dijn, 1 \%; Zanderij, 16.iii.2006, 1 \%.

\section{Stipomorpha mendax Reemer}

Fig. 42

Stipomorpha mendax Reemer, 2013: 62. Holotype ơ : Surinam, Perica (RMNH). [examined]

Ubristes fraudator (Shannon, 1927) of Van Doesburg (1966: 85).

Notes. The specimens referred to as Ubristes fraudator (Shannon) by Van Doesburg (1966) proved to belong to an undescribed species, now described by Reemer (2013b). Four specimens of this species were collected by D.C. Geijskes on four different dates at three different localities. This is remarkable, as no specimens have been found by either P.H. van Doesburg Jr. or the present author, both of whom have collected Syrphidae much more extensively than D.C. Geijskes.

New records. Charlesburg, 21.i.1964, leg. D.C. Geijskes, $1 \sigma^{\top}$; Kwatta, 1.ii.1964, leg. D.C. Geijskes, 1 \%; Ma Retraite, 9.ii.1964, leg. D.C. Geijskes, $1 \sigma^{7}$; Ma Retraite, 9.ii.1964, leg. D.C. Geijskes, $1 \sigma^{x}$; Perica, 6-20.viii.1997, 1 o'.

\section{Stipomorpha mixta (Curran)}

Fig. 41

Microdon mixtus Curran, 1940: 6. Holotype $_{\text {: Guyana, }}$ Cuyuni R. (BMNH). [examined]

? Microdon mixtus Curran: Van Doesburg (1962: 13).

Notes. Van Doesburg (1962) recorded this species from Surinam based on a female from Paramaribo, 14.xii.1957. Subsequently, Van Doesburg (1966), re- 
identified this specimen as Ubristes simillima (Hull, 1950), but remained doubtful about its true identity. Unfortunately, no specimen of Stipomorpha with corresponding label data could be found in the RMNH collection by the present author, so this matter cannot be resolved.

The specimen recorded here was captured after the collector saw it tumbling down (from the canopy?) on shrub leaves along a narrow path in dark primary forest.

New records. Brownsberg, 2.iv.2006, 1 q.

\section{Stipomorpha puerilis (van Doesburg)}

Fig. 50

Ubristes puerilis van Doesburg, 1966: 86. Holotype o: Surinam, Zanderij (RMNH). [examined]

Notes. Except for a female collected in Venezuela (Reemer 2013b), no further specimens of this species described by Van Doesburg are known.

Previous records. Zanderij, 23.ix.1960, leg. P.H. van Doesburg Jr., 1 o (holotype).

\section{Stipomorpha spuria Reemer}

Fig. 44

Stipomorpha spuria Reemer, 2013: 68. Holotype ơ: Surinam, Peperpot (RMNH). [examined]

Notes. This species is only known from the holotype. New records. Peperpot, 20.iv.2006, $1 \sigma^{\top}$ (holotype).

\section{Surimyia Reemer, 2008}

Both described species of the genus Surimyia have so far only been found in Surinam.

\section{Surimyia minutula (van Doesburg)}

Fig. 19

Ceratophya minutula van Doesburg, 1966: 89. Holotype $\sigma^{2}$ : Surinam, Zanderij (RMNH). [examined]

Paragodon minutulus (van Doesburg): Thompson (1969).

Previous records. Zanderij, 13-16.viii.1964, leg. D.C. Geijskes, $1 \sigma^{\top}$ (holotype).

\section{Surimyia rolanderi Reemer}

Fig. 20

Surimyia rolanderi Reemer, 2008: 180. Holotype $\sigma^{7}$ : Surinam, Peperpot (RMNH). [examined]

New records. Several records from Peperpot between 2 February and 27 April 2009 (as listed by Reemer 2008). The following additional specimens were found among Malaise trap material after publishing the description: Peperpot, 14-21.iii.2006, leg. M. Reemer, $10^{x} 1$ o (RMNH).

\section{Key to the Neotropical genera of Microdontinae}

A key to the genera of Microdontinae of the world was recently published by Reemer \& Ståhls (2013a). The key below is based on that key, but it is strongly simplified (50 couplets instead of 99). It contains only half the number of couplets of the world key, so in many cases it will be easier to identify Neotropical specimens using this key.

1. Vein R4 +5 without posterior appendix extending into cell $\mathrm{r} 4+5$ (Figs 77-79) ... 36

- Vein R4 + 5 with posterior appendix extending into cell $r 4+5$ (Figs $80-82) \ldots \ldots 2$

2. Abdomen constricted (club-shaped), tergite 2 parallel-sided or with posterior margin narrower than anterior margin (Figs 3438) ............................ 32

- Abdomen not constricted (oval, parallelsided or tapering), tergite 2 with posterior margin wider than anterior margin (Figs 1$33,39-52) \ldots \ldots \ldots \ldots \ldots \ldots \ldots \ldots \ldots$

3. Anepisternum with bare part limited to ventral half of the anepisternum, or entirely pilose.........................28

- Anepisternum extensively bare, with bare part reaching dorsad to above half the height of the anepisternum ............. 4

4. Propleuron (proepimeron) bare ......... 11

- Propleuron (proepimeron) pilose ..........5

5. Postero-apical corner of wing cell $\mathrm{r} 4+5$ more or less rectangular or acute, always with small appendix (Fig. 80) ........... 9

- Postero-apical corner of wing cell $\mathrm{r} 4+5$ widely rounded, sometimes with small appendix (Figs 81, 82) ..............6

6. Katepimeron more or less flat (may be a little elevated or with an ill-developed carina, but not convex), sometimes with rows of microtrichia. Abdomen narrow, clearly less than 1.5 times as wide as thorax (Figs 32, 33)...... Peradon: flavofasium-group (in part)

- Katepimeron convex, never with microtrichia. Abdomen wide, about 1.5 times as wide as thorax (Figs 1-9) .............. 7

7. Apical crossvein M1 with outward angle, usually with a small outward appendix, anteriorly recurrent (Fig. 81) ............ ...............Microdon (Chymophila)

- Apical crossvein M1 without outward angle (Fig. 82) ...................... 8 

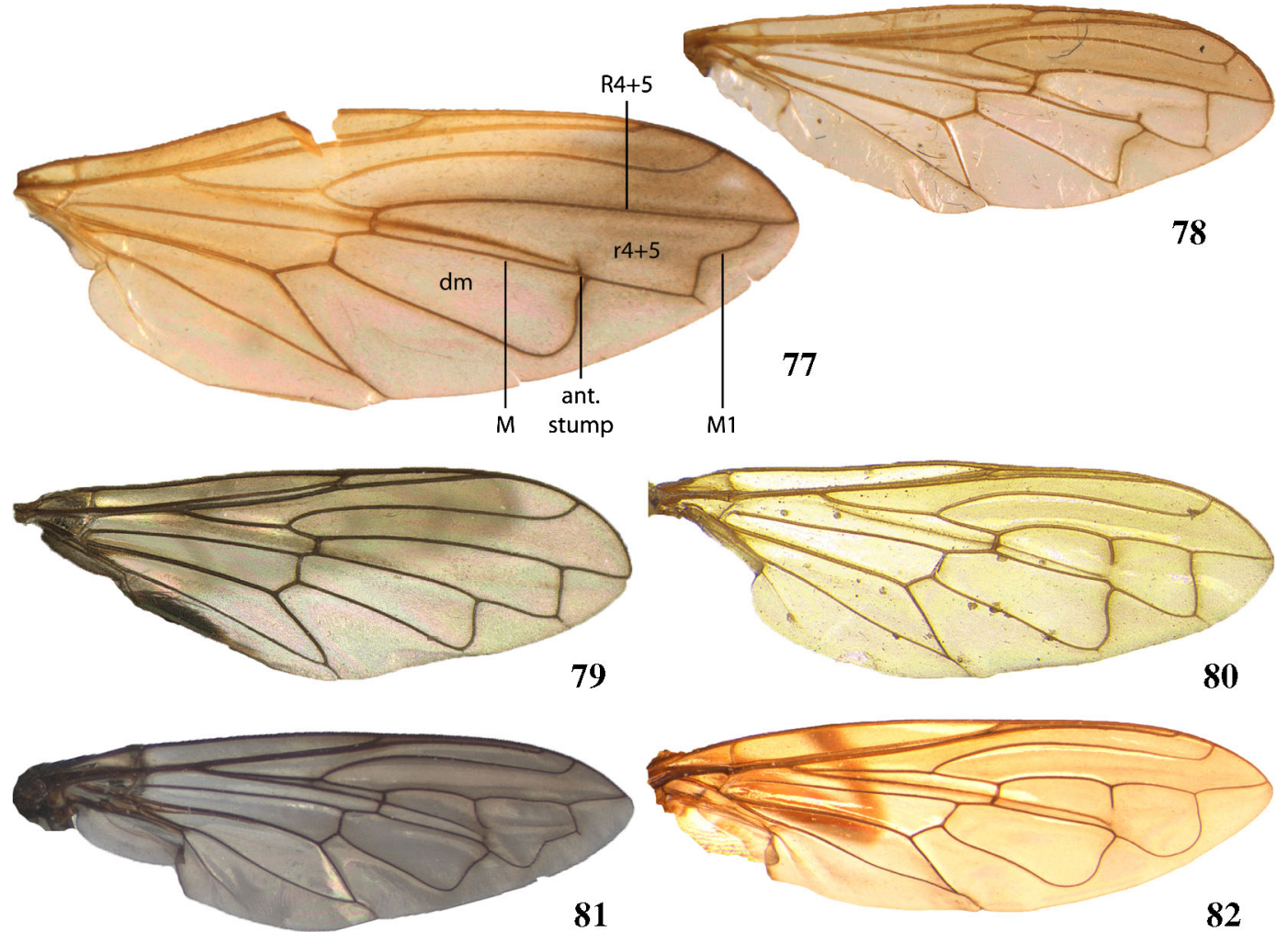

Figs 77-82. Wings of Microdontinae. - 77, Aristosyrphus; 78, Mixogaster; 79, Surimyia; 80, Ceratophya; 81, Microdon (Chymophila); 82, Microdon (Microdon). Wing terms used in the key are indicated in Fig. 77.

8. Lateral oral margins not or only slightly produced: anterolateral corners rounded (Fig. 83) ........... Microdon (Microdon) s.s.

- Lateral oral margins strongly produced: anterolateral corners angular (Fig. 84)....... ......... Microdon (Microdon): virgo-group

9. Tergites 3 and 4 not fused, able to articulate independently (Fig. 85) ... Ceratophya (in part)

- Tergites 3 and 4 fused, not able to articulate independently, although a suture between the tergites is usually visible (look at lateral margins for best judgement) . ......... 10

10. Eye bare. Male genitalia: phallus apically furcate (as in Figs 69, 72) ........ Serichlamys

- Eye pilose. Male genitalia: phallus unfurcate (as in Fig. 53) ................. Laetodon

11. Sternites 2 and 3 (often also 1 and 2) separated by unusually wide membraneous part, about as wide as sternite 2 medially or wider (Fig. 86). Antetergite enlarged, longer than tergite 1 medially, almost at level with tergite $1 \ldots \ldots \ldots \ldots \ldots$ Stipomorpha

- Sternites 2 and 3 not separated by unusually wide membraneous part. Antetergite small, shorter than or as long as tergite 1 medially, often not at level with tergite 1 but making a smaller angle ................... 12

12. Postero-apical corner of wing cell $r 4+5$ more or less rectangular or acute (usually with small appendix) (Fig. 80) .......... 23

- Postero-apical corner of wing cell $\mathrm{r} 4+5$ widely rounded (sometimes with small appendix) (Figs 81, 82) ............... 13

13. Basoflagellomere shorter than scape (Figs 83, 84).................. 19

- Basoflagellomere as long as or longer than scape (Fig. 67) . ................... 14

14. Sternite 1 pilose (sometimes only short and

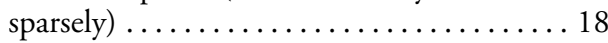

- Sternite 1 bare ...................... 15

15. Entire body with metallic green to bluish colouration, densely punctuate. Mimics of chrysidid wasps (Hymenoptera: Chrysididae) (Figs 11, 12) ............ Chrysidimyia

- At most thorax with faint metallic hues ... 16

16. Abdomen constricted basally (Fig. 34) .... ........Peradon: trivittatum-group (in part)

- Abdomen not constricted .............. 17 


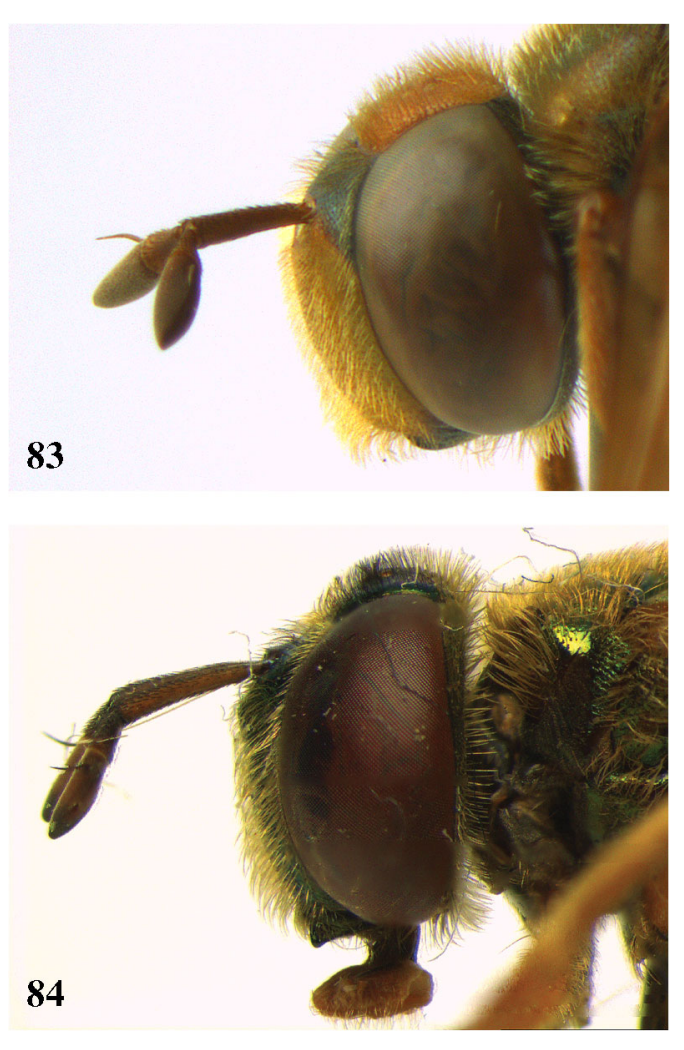

Figs 83, 84. Microdon (Microdon), head lateral. 83, sensu stricto: anterolateral corners of oral margin rounded; 84, virgo-group: anterolateral corners of oral margin angular.

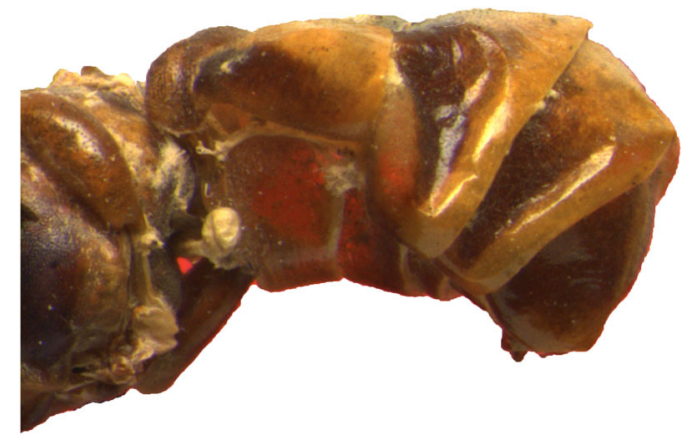

Fig. 85. Ceratophya, abdomen lateral: tergites not fused, overlapping.

17. Tergites without fasciae or vittae of golden or silver pile. Basoflagellomere always less than twice as long as scape ............. .................. Peradon: bidens-group

- Tergites usually with fasciae and/or vittae of golden or silver pile. If not, then basoflagel-

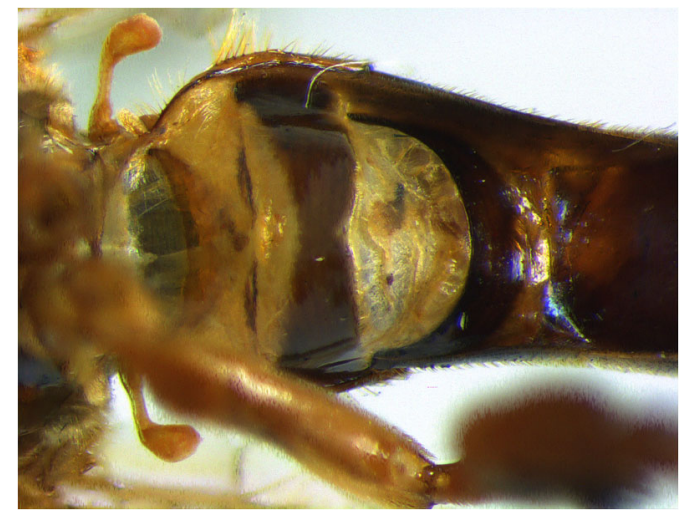

Fig. 86. Stipomorpha, base of abdomen ventral.

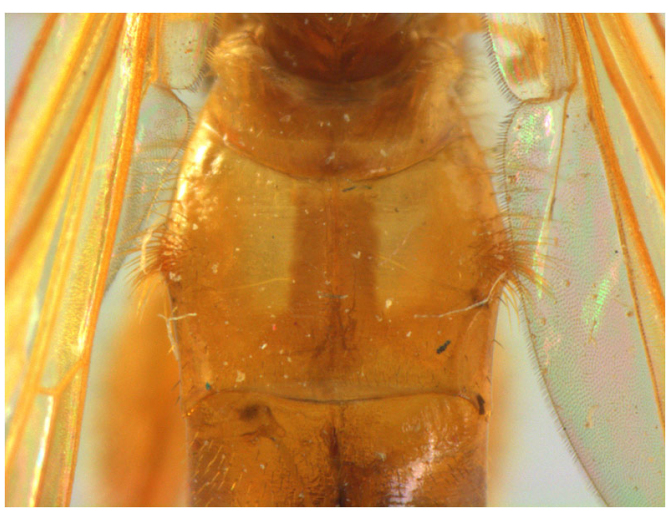

Fig. 87. Ubristes, tergite 2 dorsal.

lomere more than twice as long as scape... ........ Peradon: flavofascium-group (in part)

18. Tergite 2 with tubercle halfway on lateral margin (Fig. 87) .............. Ubristes

- Tergite 2 without tubercle on lateral margin ........... Microdon s.s. (in part: macquartii)

19. Wings hyaline, at most subtly infuscated ... 21

- Wings with contrasting black and yellow colour pattern .................... 20

20. Abdomen without conspicuous fasciae of long pile. Scutellum without calcars. $<20 \mathrm{~mm}$........ Microdon s.l.: mirabilis-group

- Abdomen with conspicuous fasciae of long, white pile; apex long, orange pilose. Scutellum with large calcars. $>20 \mathrm{~mm}$. Mimics of Eulaema (Hymenoptera: Euglossidae)...... .................Microdon (Syrphipogon)

21. Vertex convex and shining ............. ....... Pseudomicrodon (in part: biluminiferus)

- Vertex more or less flat, dull ............ 22

22. Abdomen wider than head (Figs 4-9)..... ...........Microdon s.s.: virgo-group (in part) 
- Abdomen about as wide as head (Figs 32, 33) ...... Peradon: flavofascium-group (in part)

23. Antenna shorter than distance between antennal fossa and anterior oral margin .....

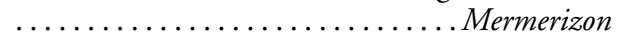

- Antenna as long as or longer than distance between antennal fossa and anterior oral margin.........................24

24. Scutellum with apical calcars...........26

- Scutellum without apical calcars, but sometimes sulcate apicomedially or with small patches of microtrichia where calcars could be expected.....................25

25. Tergites 3 and 4 not fused, able to articulate independently .............. Ceratophya

- Tergites 3 and 4 fused, not able to articulate independently, although a suture between the tergites is usually visible ............ ................ Menidon falcatus (in part)

26. Vertex convex and shining, bare or sparsely pilose only on posterior half (Figs 55, 56)

......................... Domodon

- Vertex not convex and shining, entirely pilose ......................... 27

27. Basoflagellomere oval........... Serichlamys

- Basoflagellomere sickle-shaped (Fig. 88)... .................. Menidon falcatus (in part)

28. Antenna as long as or longer than distance between antennal fossa and anterior oral margin.

- Antenna shorter than distance between antennal fossa and anterior oral margin .....

29. Tergites 3 and 4 fused, not able to articulate independently, although a suture between the tergites is usually visible (look at lateral margins for best judgement) ........... 30

- Tergites 3 and 4 not fused, able to articulate independently (Fig. 85) .......... Ceratophya

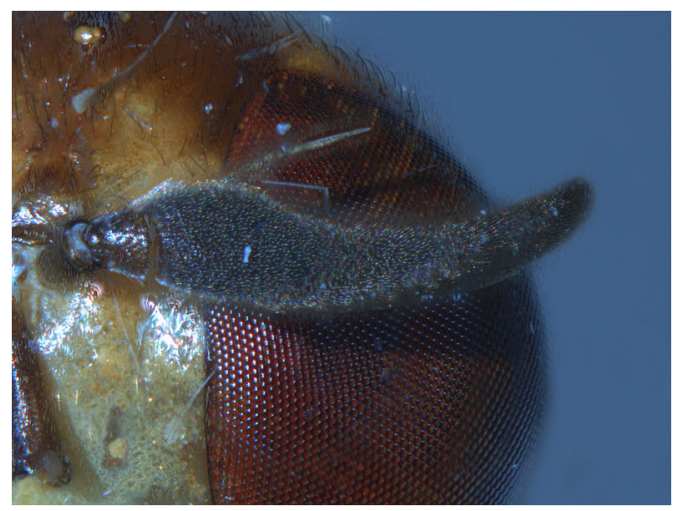

Fig. 88. Menidon, antenna.
30. Metallic green species, mimics of chrysidid wasps (Figs 11, 12) ......... Chrysidimyia

- Blackish, brownish or partly orange species ................................ 31

31. Frons without sharply demarcated concave areas and without dense golden pilosity ... ..................... Microdon (Dimeraspis)

- Frons laterally with concave area, covered with dense golden pilosity; ventrally this area is delimited by a sharply defined ridge, which runs from the lunula to the eye margin........... Thompsodon conspicillifrons

32. Transverse suture complete: extending from one notopleuron to the other........... ............... Ceriomicrodon petiolatus

- Transverse suture incomplete: not visible medially on mesoscutum .............. 33

33. Vertex convex, shining, sparsely pilose to bare (Fig. 89) ............. Pseudomicrodon

- Vertex more or less flat, dull and entirely pilose (as in Fig. 71) ............... 34

34. Tergite 2 with anterior margin about as wide as posterior margin (Fig. 34) ....... ..............Peradon: trivittatum-group

- Tergite 2 with anterior margin at least 1.5 times as wide as posterior margin (Fig. 38)

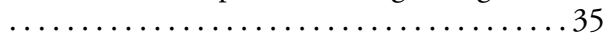

35. Katepimeron pilose (sometimes only along anterior margin)......... Rhopalosyrphus s.s.

- Katepimeron bare ........ Rhopalosyrphus s.l.

36. Vein $M$ anteriorly without small stump extending into cell $\mathrm{r} 4+5$ (Fig. 79) ........ 38

- Vein M anteriorly with small stump extending into cell $r 4+5$ (Figs 77,78$) \ldots \ldots \ldots 37$

37. Crossvein $\mathrm{r}-\mathrm{m}$ located between basal $1 / 4$ and $1 / 3$ of cell dm (Fig. 78) ....... Mixogaster

- Crossvein $\mathrm{r}-\mathrm{m}$ located within basal 1/7 of cell $\mathrm{dm}$ (Fig. 77) ............. Aristosyrphus (in part: some specimens of $A$. Primus)

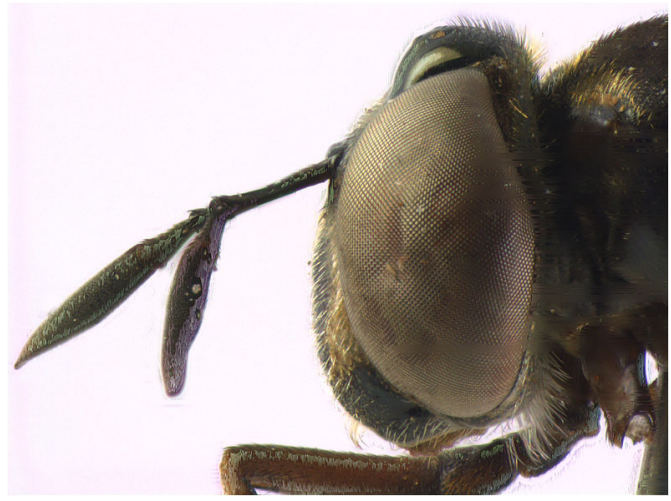

Fig. 89. Pseudomicrodon, head lateral. 


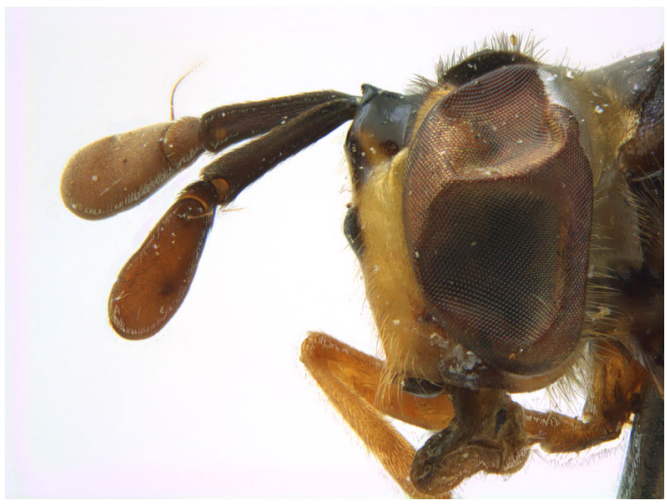

Fig. 90. Aristosyrphus (Eurypterosyrphus), head lateral.

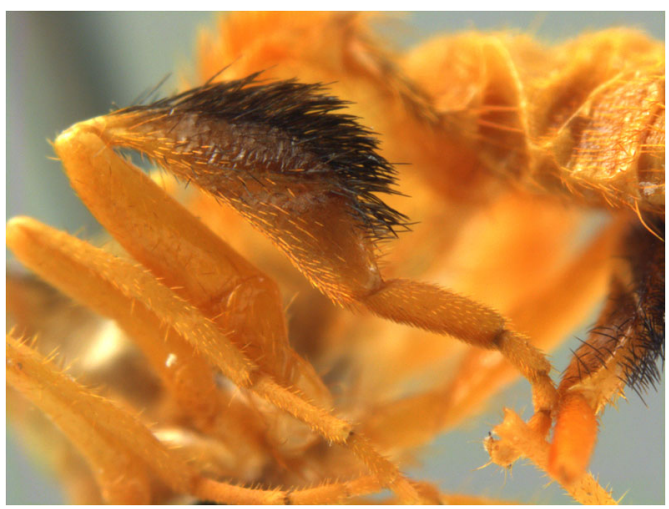

Fig. 91. Carreramyia, hind leg.

38. Face with median tubercle on dorsal half (Fig. 90) ...... Aristosyrphus (Eurypterosyrphus)

- Face without median tubercle............39

39. Vein M1 at least in anterior half (sometimes also in posterior half) oblique, more or less parallel to wing margin, making acute angle with vein $\mathrm{R} 4+5$ (Fig. 77) ... Aristosyrphus s.s.

- Vein M1 more or less straight, not parallel to wing margin, making straight angle with vein R4 + 5 (Fig. 79) ..............4 40

40. Sternites 2 and 3 (often also 1 and 2) separated by unusually wide membraneous part, about as wide as sternite 2 medially or wider (Fig. 86). Antetergite of tergite 1 enlarged, longer than tergite 1 medially, almost at level with tergite $1 \ldots \ldots \ldots$...... Stipomorpha

- Sternites 2 and 3 not separated by unusually wide membraneous part. Antetergite small, shorter than or as long as tergite 1 medially, often not at level with tergite 1 but making a smaller angle ....................4 41

41. Postpronotum bare ................ 49

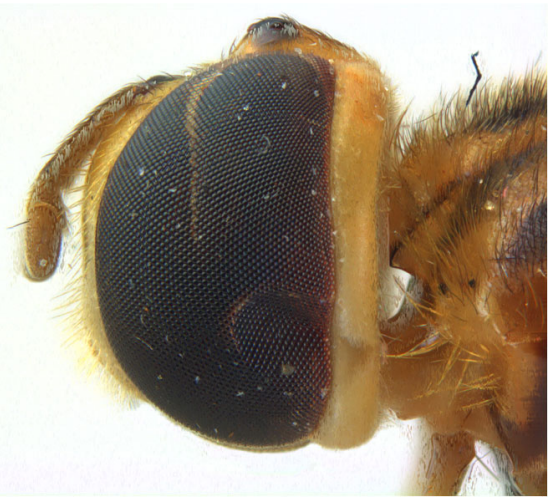

Fig. 92. Rhoga, head lateral.

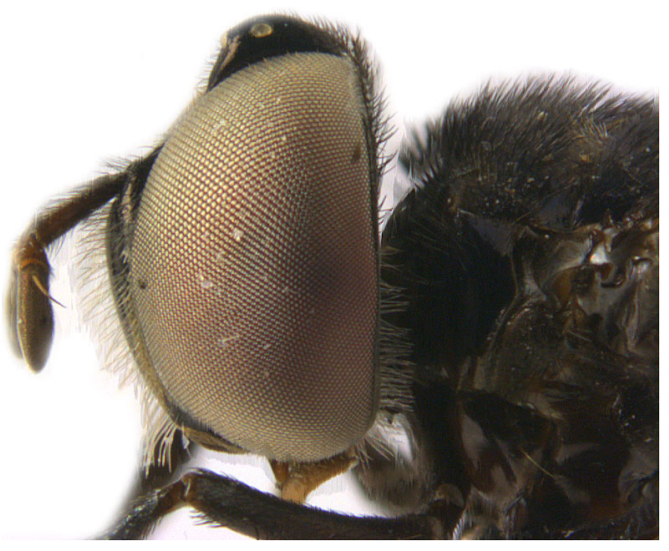

Fig. 93. Hypselosyrphus, head lateral.

- Postpronotum pilose................. 82

42. Hind tibiae with short, appressed pilosity (Fig. 91) ....................... 45

- Hind tibiae with long, brushy pilosity, resembling the tibial floccus of bees ....... 43

43. Antenna very long, longer than height of head, basoflagellomere bifurcate in male . .

Carreramyia

- Antenna short or moderately long, shorter than height of head (in case of doubt: basoflagellomere shorter than scape) ....... 44

44. Occiput wide, wider than distance between anterior and posterior ocelli (Fig. 92) .. Rhoga

- Occiput narrow, narrower than disctance between anterior and posterior ocelli (Fig. 93) ............ Hypselosyrphus (part)

45. Antenna very long, longer than height of head, basoflagellomere bifurcate in male. . . 48

- Antenna short or moderately long, shorter than height of head..................46 
46. Abdomen narrow, more or less parallelsided. Sternites 3-4 narrower than sternite 2 ...................... Paramicrodon

- Abdomen oval. Sternites 3-4 wider than sternite $2 \ldots \ldots \ldots \ldots \ldots \ldots \ldots \ldots 47$

47. Crossvein $\mathrm{r}-\mathrm{m}$ located between basal $1 / 8$ and $1 / 4$ of cell $\mathrm{dm} . . . .$. Hypselosyrphus (part)

- Crossvein $\mathrm{r}-\mathrm{m}$ located almost at same level as base of cell $\mathrm{dm}$............... Paragodon

48. Abdomen oval, short: approximately 1.5 times as long as wide ........ Schizoceratomyia

- Abdomen elongate, long: more than twice as long as wide......... Undescribed genus \#2

49. Antenna long, at least as long as distance between antennal fossa and anterior oral margin. Basoflagellomere multifurcate in male .......................... Masarygus

- Antenna short, shorter than distance between antennal fossa and anterior oral margin. Basoflagellomere unfurcate ........ 50

50. Thorax and abdomen partly yellow... Surimyia

- Thorax and abdomen entirely black ... Piruwa

\section{Acknowledgements}

In addition to those mentioned in the acknowledgements of my previous paper on Syrphidae of Surinam (Reemer 2010), I would like to thank Daniele Sommaggio for providing information on the Rondani types in the MIZUN collection in Naples, and Frank Stokvis (Naturalis Biodiversity Center, Leiden) for his help with the making of the photographs.

\section{References}

Carrera, M., H. de Souza Lopes \& J. Lane, 1947. Contribuição ao conhecimento dos "Microdontinae" Neotrópicos e descrição de duas novas esécies de "Nausigaster" Williston (Diptera, Syrphidae). - Revista Brasileira de Biologia 7: 471-486.

Cheng, X.-Y. \& F.C. Thompson, 2008. A generic conspectus of the Microdontinae (Diptera: Syrphidae) with the description of two new genera from Africa and China. - ZooTaxa 1879: 21-48.

Curran, C.H., 1925. New American Diptera II. - Annals and Magazine of Natural History, $9^{\text {th }}$ series, 16: 338354.

Curran, C.H., 1934. The Diptera of Kartabo, Bartica District, British Guiana, with descriptions of new species from other British Guiana localities. - Bulletin of the American Museum of Natural History 46: 287-532.

Curran, C.H., 1940. Some new Neotropical Syrphidae (Diptera). - American Museum Novitates 1086: 1-14.

Curran, C.H., 1941. New American Syrphidae. - Bulletin of the American Museum of Natural History 78: 243304.
Doesburg Sr., P.H. van, 1962. Preliminary list of Syrphidae known from Suriname and British and French Guiana. - Studies on the Fauna of Suriname and other Guyanas 5: 1-33.

Doesburg Sr., P.H. van, 1966. Syrphidae from Suriname. Additional records and descriptions. - Studies on the Fauna of Suriname and other Guyanas 9: 61-107.

Hull, F.M., 1943. Some flies of the genus Microdon in the British Museum (Natural History). - Annals and Magazine of Natural History 10: 702-720.

Hull, F.M., 1949. The morphology and inter-relationships of the genera of syrphid flies, recent and fossil. Transactions of the Zoological Society 26: 257-408.

Lynch Arribálzaga, F., 1891. Dipterologia Argentina (Syrphidae). - Anales de la Sociedad scientific Argentina 32: 194-202.

Macquart, J.M., 1846. Diptères exotiques nouveaux ou peu connus. Supplément. - Memoires de la Société des Sciences, de l'Agriculture et des Arts de Lille (1845) 1844: 133-364, 20 pls.

Macquart, J.M., 1848. Diptères exotiques nouveaux ou peu connus. Suite du $2^{\text {me }}$ supplement. - Memoires de la Société des Sciences, de l'Agriculture et des Arts de Lille 1847(2): 161-237, 7 pls.

Marinoni, K. \& F.C. Thompson, 2003. Flower flies of southeastern Brazil (Diptera: Syrphidae). Part I. Introduction and new species. - Studia Dipterologica 10: 565-578.

Reemer, M., 2008. Surimyia, a new genus of Microdontinae, with notes on Paragodon Thompson (Diptera: Syrphidae). - Zoölogische Mededelingen 82: 177-188.

Reemer, M., 2010. A second survey of Surinam Syrphidae (Diptera): introduction and Syrphinae. - Tijdschrift voor Entomologie 153: 163-196.

Reemer, M., 2012. Natural history of Microdontinae (Diptera: Syrphidae): a review. - In: Reemer, M., Unravelling a hotchpotch. Phylogeny and classification of the Microdontinae (Diptera: Syrphidae). PhD thesis, Leiden University, 11-23 pp.

Reemer, M., 2013a. Review and phylogenetic evaluation of associations between Microdontinae (Diptera: Syrphidae) and ants (Hymenoptera: Formicidae). - Psyche, DOI:10.1155/2013/538316.

Reemer, M., 2013b. Taxonomic exploration of Neotropical Microdontinae (Diptera: Syrphidae) mimicking stingless bees. - ZooTaxa 3697: 1-88.

Reemer, M. \& G. Ståhls, 2013a. Generic revision and species classification of Microdontinae (Diptera, Syrphidae). - ZooKeys 288: 1-213.

Reemer, M. \& G. Ståhls, 2013b. Phylogenetic relationships of Microdontinae (Diptera: Syrphidae) based on molecular and morphological characters. - Systematic Entomology 38: 661-688.

Rondani, C., 1848. Esame di varie specie d'insetti ditteri Brasiliani. - Studi Entomologici 1: 63-112.

Schmid, V.S., M.N. Morales, L. Marinoni, R. Kamke, J. Steiner \& A. Zillikens. Natural history and morphology of Microdon biluminiferus and its parasitic relation- 
ship with ants nesting in bromeliads. - Journal of Insect Science. In press.

Shannon, R.C., 1927. A review of the South American two-winged flies of the family Syrphidae. - Proceedings of the United States National Museum 70: 1-33.

Thompson, F.C., 1969. A new genus of Microdontine flies (Diptera: Syrphidae) with notes on the placement of the subfamily. - Psyche 76: 74-85.

Thompson, F.C., 1981. The flower flies of the West Indies (Diptera: Syrphidae). - Memoirs of the Entomological Society of Washington 9: 1-200.

Thompson, F.C., 2012. Fabulous flower flies for famous fly fanatics. - Canadian Entomologist 144: 1-16.
Thompson, F.C., J.R. Vockeroth \& Y.S. Sedman, 1976. Family Syrphidae. - A catalogue of the Diptera of the Americas south of the United States 46: 1-195.

Thompson, F.C., G.E. Rotheray \& M.A. Zumbado, 2010. Syrphidae (flower flies). - In: Brown, B.V. et al. (eds.), Manual of Central American Diptera: Volume 2. NRC Research Press, Ottawa, 763-792 pp.

Weems Jr., R.V., F.C. Thompson, G. Rotheray \& M.A. Deyrup, 2003. The genus Rhopalosyrphus (Diptera: Syrphidae). - Florida Entomologist 86: 186193.

Received: July 25, 2013

Accepted: December 18, 2013 
